\title{
A global perspective on aerosol from low-volatility organic compounds
}

\author{
H. O. T. Pye and J. H. Seinfeld \\ Department of Chemical Engineering, California Institute of Technology, Pasadena, CA, USA \\ Received: 21 January 2010 - Published in Atmos. Chem. Phys. Discuss.: 11 February 2010 \\ Revised: 28 April 2010 - Accepted: 2 May 2010 - Published: 12 May 2010
}

\begin{abstract}
Global production of organic aerosol from primary emissions of semivolatile (SVOCs) and intermediate (IVOCs) volatility organic compounds is estimated using the global chemical transport model, GEOS-Chem. SVOC oxidation is predicted to be a larger global source of net aerosol production than oxidation of traditional parent hydrocarbons (terpenes, isoprene, and aromatics). Using a prescribed rate constant and reduction in volatility for atmospheric oxidation, the yield of aerosol from SVOCs is predicted to be about $75 \%$ on a global, annually-averaged basis. For IVOCs, the use of a naphthalene-like surrogate with different high- $\mathrm{NO}_{\mathrm{x}}$ and low- $\mathrm{NO}_{\mathrm{x}}$ parameterizations produces a global aerosol yield of about $30 \%$, or roughly $5 \mathrm{Tg} / \mathrm{yr}$ of aerosol. Estimates of the total global organic aerosol source presented here range between 60 and $100 \mathrm{Tg} / \mathrm{yr}$. This range reflects uncertainty in the parameters for SVOC volatility, SVOC oxidation, SVOC emissions, and IVOC emissions, as well as wet deposition. The highest estimates result if SVOC emissions are significantly underestimated (by more than a factor of 2) or if wet deposition of the gas-phase semivolatile species is less effective than previous estimates. A significant increase in SVOC emissions, a reduction of the volatility of the SVOC emissions, or an increase in the enthalpy of vaporization of the organic aerosol all lead to an appreciable reduction of prediction/measurement discrepancy. In addition, if current primary organic aerosol (POA) inventories capture only about one-half of the SVOC emission and the Henrys Law coefficient for oxidized semivolatiles is on the order of $10^{3} \mathrm{M} / \mathrm{atm}$, a global estimate of OA production is not inconsistent with the top-down estimate of $140 \mathrm{Tg} / \mathrm{yr}$ by (Goldstein and Galbally, 2007). Additional information
\end{abstract}

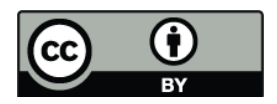

Correspondence to: J. H. Seinfeld (seinfeld@caltech.edu) is needed to constrain the emissions and treatment of SVOCs and IVOCs, which have traditionally not been included in models.

\section{Introduction}

Organics represent a significant fraction of the aerosol mass in the atmosphere (Zhang et al., 2007). Bottom-up estimates of particulate matter concentrations, such as those that would be used to estimate aerosol radiative forcings, visibility, or implications for public health, must be able to represent the processes critical for organic aerosol formation. Work by Lipsky and Robinson (2006) and Robinson et al. (2007) as well as others (Huffman et al., 2009a,b) indicates that what has traditionally been considered non-volatile primary organic aerosol (POA) is actually a dynamic system of semivolatile species that partition between the gas and aerosol phases as well as undergo gas-phase oxidation to form species of different volatilities that can condense to form secondary organic aerosol (SOA). We present the first estimates of the contribution of primary semivolatile organic compounds and other low-volatility organic compounds to global aerosol production.

Emissions of low-volatility organic compounds can be subdivided somewhat arbitrarily into two classes based on volatility (Donahue et al., 2006): semivolatile organic compounds (SVOCs) and intermediate volatility organic compounds (IVOCs). Semivolatile organic compounds are those that partition directly between the gas and aerosol phases under ambient conditions and include compounds with saturation concentrations roughly between 0.1 and $10^{4} \mu \mathrm{g} / \mathrm{m}^{3}$. SVOC emissions include traditional POA plus any vapor phase species that are in direct equilibrium with the particle

Published by Copernicus Publications on behalf of the European Geosciences Union. 
phase. SVOCs include species such as large polycyclic aromatic hydrocarbons (PAHs) (e.g. fluoranthene) and long $n$ alkanes (e.g. $n$-pentacosane).

Intermediate volatility organic compounds (IVOCs) are more volatile than SVOCs and roughly span saturation concentrations from $10^{4}$ to $10^{6} \mu \mathrm{g} / \mathrm{m}^{3}$. Since IVOCs partition appreciably to the aerosol phase only under very high aerosol loadings (loadings that typically exceed those found in urban areas), IVOCs are assumed to be emitted entirely in the gas phase. However, due to their relatively low volatility compared to traditional SOA precursors, IVOCs can be easily converted to lower volatility products that partition to the aerosol phase. Species that would fall in the IVOC range include small PAHs (e.g. naphthalene), intermediate length alkanes (e.g. $n$-hexadecane), and phenols.

Species with saturation concentrations below $0.1 \mu \mathrm{g} / \mathrm{m}^{3}$ are also emitted. Under most atmospherically relevant conditions, such species partition essentially entirely to the aerosol phase and can be considered non-volatile. They are estimated to comprise less than 5\% of traditional POA inventories (Grieshop et al., 2009b).

A major obstacle to representing low-volatility organic compounds in atmospheric models is that the identities of many of the species that fall in the SVOC and IVOC categories are unknown. In addition, current inventories used in atmospheric models may not include many of the IVOC emissions (for example, see the work by Shrivastava et al., 2008). From a modeling perspective, an efficient lumping mechanism must be developed. Since the volatility represents the tendency of a species to be in the particle phase, an effective approach is to lump species based on volatility. Information would then be needed about the volatility of the emissions and how the volatility changes with atmospheric processing. A two-dimensional approach using a volatility basis set combined with carbon oxidation state has also been proposed (Jimenez et al., 2009).

Isothermal chamber dilution (Grieshop et al., 2009b), thermodenuder systems (Grieshop et al., 2009b; Huffman et al., 2009b), and dilution samplers (Lipsky and Robinson, 2006) have been used to constrain the volatility of organic compound emissions. The volatility distribution of SVOC emissions from various sources, such as wood burning and diesel exhaust, show sufficient similarity that they can be represented with a single volatility distribution (Robinson et al., 2007; Shrivastava et al., 2006; Grieshop et al., 2009b). Volatility fits of SVOC emissions have typically been assumed to be directly applicable to existing POA inventories based on the assumption that emission factors tend to be measured at unrealistically high organic loadings and often use filters that collect gas phase emissions as well (Grieshop et al., 2009b). IVOC emissions must typically be estimated as they are not captured by traditional POA sampling techniques. IVOC emissions may also vary considerably from source to source (Shrivastava et al., 2008; Grieshop et al., 2009a).
Aerosol formation from SVOCs, IVOCs, and their oxidation products has been implemented in regional models such as PMCAMx and CHIMERE (Robinson et al., 2007; Shrivastava et al., 2008; Murphy and Pandis, 2009; Hodzic et al., 2010) as well as box models (Dzepina et al., 2009; Grieshop et al., 2009a). The SVOCs, and IVOCs if applicable, are typically represented using the volatility basis set framework (Donahue et al., 2006) and allow for oxidation in the gas phase and formation of lower volatility products. Replacing the traditional non-volatile POA with semivolatile POA in regional models has lead to improvements in the urban to regional organic aerosol (OA) concentration ratio (Robinson et al., 2007; Shrivastava et al., 2008) and predicts an ambient aerosol more dominated by oxygenated species (Shrivastava et al., 2008; Murphy and Pandis, 2009), consistent with observations.

In this work, organic aerosol formation from SVOCs and IVOCs is studied using the global chemical transport model, GEOS-Chem. Section 2 describes the global model framework as well as the emissions and atmospheric transformation of SVOCs and IVOCs. Results are presented in Sect. 3 in terms of predicted aerosol levels, global budgets, and modern vs. fossil carbon. The paper finishes by addressing model uncertainties (Sect. 4) and placing the results in the larger context of top-down vs. bottom-up global aerosol budgets (Sect. 5).

\section{Model description}

\subsection{Global model}

The global chemical transport model, GEOS-Chem (version 8-01-04, http://acmg.seas.harvard.edu/geos/), is used to simulate year 2000 organic aerosol concentrations. Simulations are conducted at $2^{\circ}$ latitude by $2.5^{\circ}$ longitude horizontal resolution using GEOS-4 assimilated meteorology with 30 vertical layers going up to $0.01 \mathrm{hPa}$ for baseline simulations. For computational speed, and in preparation for climate changeorganic aerosol interaction studies, sensitivity tests are performed at $4^{\circ}$ latitude by $5^{\circ}$ longitude horizontal resolution with 23 vertical levels up to $0.002 \mathrm{hPa}$ using GISS GCM Model III meteorology (Rind et al., 2007; Wu et al., 2007, 2008). All simulations are conducted for year 2000 with a minimum of 11 months of initialization. Simulations include fully coupled ozone- $\mathrm{NO}_{\mathrm{x}}$-hydrocarbon chemistry (Bey et al., 2001), and formation of inorganic (Park et al., 2004; Pye et al., 2009) and organic aerosol (Park et al., 2003, 2006; Henze and Seinfeld, 2006; Liao et al., 2007; Henze et al., 2008).

\subsection{Absorptive partitioning}

Formation of organic aerosols occurs by absorptive partitioning (Odum et al., 1996), and the partitioning framework used here is based on the work of Chung and Seinfeld (2002). 
An equilibrium partitioning coefficient, $K_{\mathrm{OM}, i}$, describing the partitioning between the gas and aerosol phases of a semivolatile species can be calculated assuming a pseudoideal solution and absorptive partitioning theory (Pankow, 1994):

$K_{\mathrm{OM}, i}=\frac{R T}{\tilde{M}_{i} \gamma_{i} P_{i}^{\mathrm{vap}}}$

where $R$ is the gas constant, $T$ is temperature, $\tilde{M}_{i}$ is the molecular weight, $\gamma_{i}$ is the activity coefficient of compound $i$ in the aerosol phase, and $P_{i}^{\text {vap }}$ is the vapor pressure of pure species $i$ at temperature $T$. Absorptive partitioning can also be described using a saturation concentration, $C_{i}^{*}$, which is the inverse of the equilibrium partitioning coefficient (for a discussion of the difference between $C_{i}^{*}$ and $K_{\mathrm{OM}, i}$ see the supporting material from Donahue et al., 2006):

$$
K_{\mathrm{OM}, i}=\frac{1}{C_{i}^{*}}
$$

In terms of concentrations of the semivolatile $i,\left[\mathrm{G}_{i}\right]$ and $\left[\mathrm{A}_{i}\right]$, in the gas and aerosol phases, respectively,

$K_{\mathrm{OM}, i}=\frac{\left[\mathrm{A}_{i}\right]}{\left[\mathrm{G}_{i}\right]\left[M_{\mathrm{o}}\right]}$

where $\left[M_{\mathrm{O}}\right]$ is the concentration of particle-phase absorptive material into which the semivolatile compound can partition. In this study, the partitioning medium includes only the particle-phase organics (inorganic constituents and water included in some studies are not considered here). Primary and secondary organic aerosol is assumed to form a single absorbing phase. When non-volatile POA is present,

$\left[M_{\mathrm{o}}\right]=[\mathrm{POA}]+\sum_{i}\left[\mathrm{~A}_{i}\right]$,

and if POA is semivolatile, this reduces to,

$\left[M_{\mathrm{o}}\right]=\sum_{i}\left[\mathrm{~A}_{i}\right]$.

Combining Eqs. (3) and (4) or (5) as appropriate, along with a mass balance, yields an implicit equation for $M_{\mathrm{o}}$. Organic aerosol will form only when (i.e. the implicit equation for $M_{\mathrm{O}}$ will only have a solution when) (Chung and Seinfeld, 2002),

$\sum_{i} K_{\mathrm{OM}, i}\left(\left[\mathrm{~A}_{i}\right]+\left[\mathrm{G}_{i}\right]\right)>1$.

Simulations indicate that this condition is generally satisfied with a few exceptions. Formation of organic aerosol through other means, such as cloud processing or reactive uptake, are not considered in the present study.

\subsection{SOA from traditional precursors}

SOA from traditional precursors follows earlier studies for terpenes (Chung and Seinfeld, 2002), isoprene (Henze and Seinfeld, 2006), and aromatics (Henze et al., 2008). Parent hydrocarbons are oxidized in the gas-phase to form a series of semivolatile species,

$\mathrm{HC}+\mathrm{O}_{\mathrm{x}} \rightarrow \alpha_{1} \mathrm{P}_{1}+\alpha_{2} \mathrm{P}_{2}+\ldots$

where $\alpha_{1}, \alpha_{2}, \ldots$ are mass-based stoichiometric coefficients for products $\mathrm{P}_{1}, \mathrm{P}_{2}, \ldots$ Sometimes, only one semivolatile or nonvolatile product is necessary to represent chamber data (like for low- $\mathrm{NO}_{\mathrm{x}}$ aromatic oxidation ( $\mathrm{Ng}$ et al., 2007; Chan et al., 2009) or nitrate radical oxidation of terpenes (Chung and Seinfeld, 2002)), but typically two semivolatile products have been used (Odum et al., 1996) with partitioning parameters, $\alpha_{i}$ and $K_{\mathrm{OM}, i}$, determined by fits to laboratory data. Models such as PMCAMx have been used to investigate the possibility of continued aging of the SOA formed from traditional parent hydrocarbons due to continued $\mathrm{OH}$ oxidation of the gas-phase semivolatile species (Lane et al., 2008). In the present work, traditional SOA species are not considered subject to continued oxidation beyond that captured in chamber studies.

\subsection{Aerosol from SVOCs}

POA is defined to be any SVOC that partitions directly to the particle phase after emission without undergoing oxidation. In source regions, there is likely to be net POA production, but as air masses move to more remote regions, POA will be driven out of the particle phase due to dilution and oxidation of the gas-phase species. Oxidation of the primary gas-phase SVOCs can lead to lower volatility products that partition to make SOA.

\subsubsection{SVOC emissions}

SVOCs from all sources are assumed to be emitted as two semivolatile surrogate species, $\mathrm{SVOC}_{1}$ and $\mathrm{SVOC}_{2}$, in roughly equal fractions of 0.49 and 0.51 based on the work by Shrivastava et al. (2006) and Lipsky and Robinson (2006). Partitioning coefficients for $\mathrm{SVOC}_{1}$ and $\mathrm{SVOC}_{2}$ are given in Table 1 and correspond to saturation concentrations of roughly 1600 and $20 \mu \mathrm{g} / \mathrm{m}^{3}$. Under most atmospherically relevant conditions, only the lower volatility component is expected to partition appreciably to the aerosol phase.

The SVOC emissions are based on the traditional nonvolatile POA emission inventory used in GEOS-Chem (Park et al., 2003, 2006). The non-volatile POA inventory includes contributions from biomass burning, biofuel burning, and anthropogenic sources (Table 2 and Fig. 1). Monthly biomass burning emissions are based on the Global Fire and Emission Database version 2 (GFEDv2) for year 2000 (van der Werf et al., 2006). Global biofuel and anthropogenic organic 
Table 1. Low-volatility organic compounds.

\begin{tabular}{|c|c|c|c|c|c|}
\hline Species & Description & $\alpha^{\mathrm{a}}$ & $\begin{array}{c}K_{\mathrm{OM}}^{\mathrm{b}} \\
{\left[\mathrm{m}^{3} / \mu \mathrm{g}\right]}\end{array}$ & $\begin{array}{c}C^{*} \\
{\left[\mu \mathrm{g} / \mathrm{m}^{3}\right]}\end{array}$ & Reference \\
\hline $\mathrm{SVOC}_{1}$ & primary SVOC emission & $0.49^{\mathrm{c}}$ & 0.0006 & 1646 & Shrivastava et al. (2006) \\
\hline $\mathrm{SVOC}_{2}$ & primary SVOC emission & $0.51^{\mathrm{c}}$ & 0.05 & 20 & Shrivastava et al. (2006) \\
\hline $\mathrm{O}-\mathrm{SVOC}_{1}$ & oxidized $\mathrm{SVOC}_{1}$ & 1.5 & 0.06 & 16.46 & Grieshop et al. (2009a) \\
\hline $\mathrm{O}-\mathrm{SVOC}_{2}$ & oxidized $\mathrm{SVOC}_{2}$ & 1.5 & 5.0 & 0.20 & Grieshop et al. (2009a) \\
\hline IVOC & primary IVOC emission $^{\mathrm{d}}$ & NA & $1 \times 10^{-5}$ & $10^{5}$ & \\
\hline $\mathrm{O}-\mathrm{IVOC}_{\mathrm{N}, 1}$ & high $\mathrm{NO}_{\mathrm{x}}$ IVOC oxidation product ${ }^{\mathrm{d}}$ & 0.21 & 0.59 & 1.69 & Chan et al. (2009) \\
\hline $\mathrm{O}-\mathrm{IVOC}_{\mathrm{N}, 2}$ & high $\mathrm{NO}_{\mathrm{x}}$ IVOC oxidation product ${ }^{\mathrm{d}}$ & 1.07 & 0.0037 & 270 & Chan et al. (2009) \\
\hline $\mathrm{O}-\mathrm{IVOC}_{\mathrm{H}, 1}$ & low $\mathrm{NO}_{\mathrm{x}}$ IVOC oxidation product ${ }^{\mathrm{d}}$ & 0.73 & 10000 & 0.0001 & Chan et al. (2009) \\
\hline
\end{tabular}

a See Reaction (R1).

$\mathrm{b}$ Reference temperature for SVOC parameters is $300 \mathrm{~K}$. IVOC SOA reference temperature is $299 \mathrm{~K}$.

${ }^{\mathrm{c}}$ Fraction of total SVOC emissions.

${ }^{\mathrm{d}}$ IVOC behavior based on naphthalene.

Table 2. Emissions of primary low-volatility organic compounds (year 2000).

\begin{tabular}{lcccc}
\hline Species & $\begin{array}{c}\text { Biomass burning } \\
{[\text { Tg C/yr] }}\end{array}$ & $\begin{array}{c}\text { Biofuel burning } \\
{[\text { Tg C/yr] }}\end{array}$ & $\begin{array}{c}\text { Anthropogenic sources } \\
\text { [Tg C/yr] }\end{array}$ & $\begin{array}{c}\text { Total } \\
{[\mathrm{Tg} \mathrm{C} / \mathrm{yr}]}\end{array}$ \\
\hline Traditional non-volatile POA & 19 & 7.1 & 2.7 & 29 \\
SVOCs & 24 & 9.0 & 3.4 & 37 \\
Naphthalene $^{\mathrm{b}}$ & 0.09 & 0.05 & 0.09 & 0.22 \\
IVOC surrogate $^{\text {IVOC }}$ & 5.7 & 3.2 & 5.8 & 15 \\
\hline
\end{tabular}

a Excluding biomass and biofuel burning.

$\mathrm{b}$ The baseline naphthalene emission inventory is used only to obtain the spatial distribution of IVOC emissions.

carbon emissions are from the technology-based inventory by Bond et al. (2004). Over North America, anthropogenic emissions are superseded with those based on work by Cooke et al. (1999). US biofuel emissions are constructed based on residential and industrial wood fuel consumption, as implemented in the work of Park et al. (2003). The scaling and seasonal distribution of US anthropogenic and biofuel organic carbon (OC) emissions are also detailed in the work of Park et al. (2003).

Providing a global estimate of SVOC emissions is difficult due to the fact that it is unclear what portion of the SVOCs traditional POA represents, and traditional POA emissions, themselves are uncertain. Estimates of the traditional POA emission rate in global models has ranged from 17 to $142 \mathrm{Tg} / \mathrm{yr}$ as summarized in the work of Farina et al. (2010). Note that since biomass burning is a significant POA contributor, emissions of SVOCs likely vary from year to year as different areas become more or less prone to burning. Part of the uncertainty in global OC emissions, estimated at a factor of two in the work by Bond et al. (2004), is likely due to the fact that traditional POA inventories try to capture organic aerosol emissions over all atmospherically relevant conditions using measurements or observations of emission factors under a single or limited set of conditions in terms of temperature and organic aerosol loadings. For a species that is semivolatile, like POA, one set of conditions will not characterize the emissions well.

Debate continues on whether traditional POA inventories represent most SVOC emissions or a very limited subset. POA emission factors are often obtained under organic concentrations higher than atmospherically relevant, which may force organic vapors that would be in the gas phase under ambient conditions into the particle phase during sampling. Under such conditions, the POA inventory may be a good representation of SVOC emissions. However, an examination of the Schauer et al. (2001) inventory for wood burning, which gives OC emission factors consistent with those used in the GFEDv2 biomass burning inventory, shows individual PAH compounds with saturation concentrations of 12,100 , and $9 \times 10^{3} \mu \mathrm{g} / \mathrm{m}^{3}$ being emitted 91,56 , and $4 \%$ in the particle phases. Thus, compounds over the entire SVOC volatility range exhibit appreciable mass in the gas and particle phase. Furthermore, models using non-volatile POA tend to underestimate, not overestimate, ambient organic aerosol concentrations (Heald et al., 2005; Liao et al., 2007). We proceed by assuming traditional non-volatile POA inventories likely represent a subset of SVOC emissions. 
Table 3. Parameters for SVOC oxidation.

\begin{tabular}{lccc}
\hline Parameter & This work & Robinson et al. (2007) & Grieshop et al. (2009a) \\
\hline Gas-phase OH rate constant $\left[\mathrm{cm}^{3} \mathrm{molec}^{-1} \mathrm{~s}^{-1}\right]$ & $2 \times 10^{-11}$ & $4 \times 10^{-11}$ & $2 \times 10^{-11}$ \\
Reduction in volatility per reaction & $100 \times$ & $10 \times$ & $100 \times$ \\
Increase in mass per reaction & $50 \%$ & $7.5 \%$ & $40 \%$ \\
Number of oxidation reactions per parent hydrocarbon & 1 & $>1$ & $>1$ \\
\hline
\end{tabular}

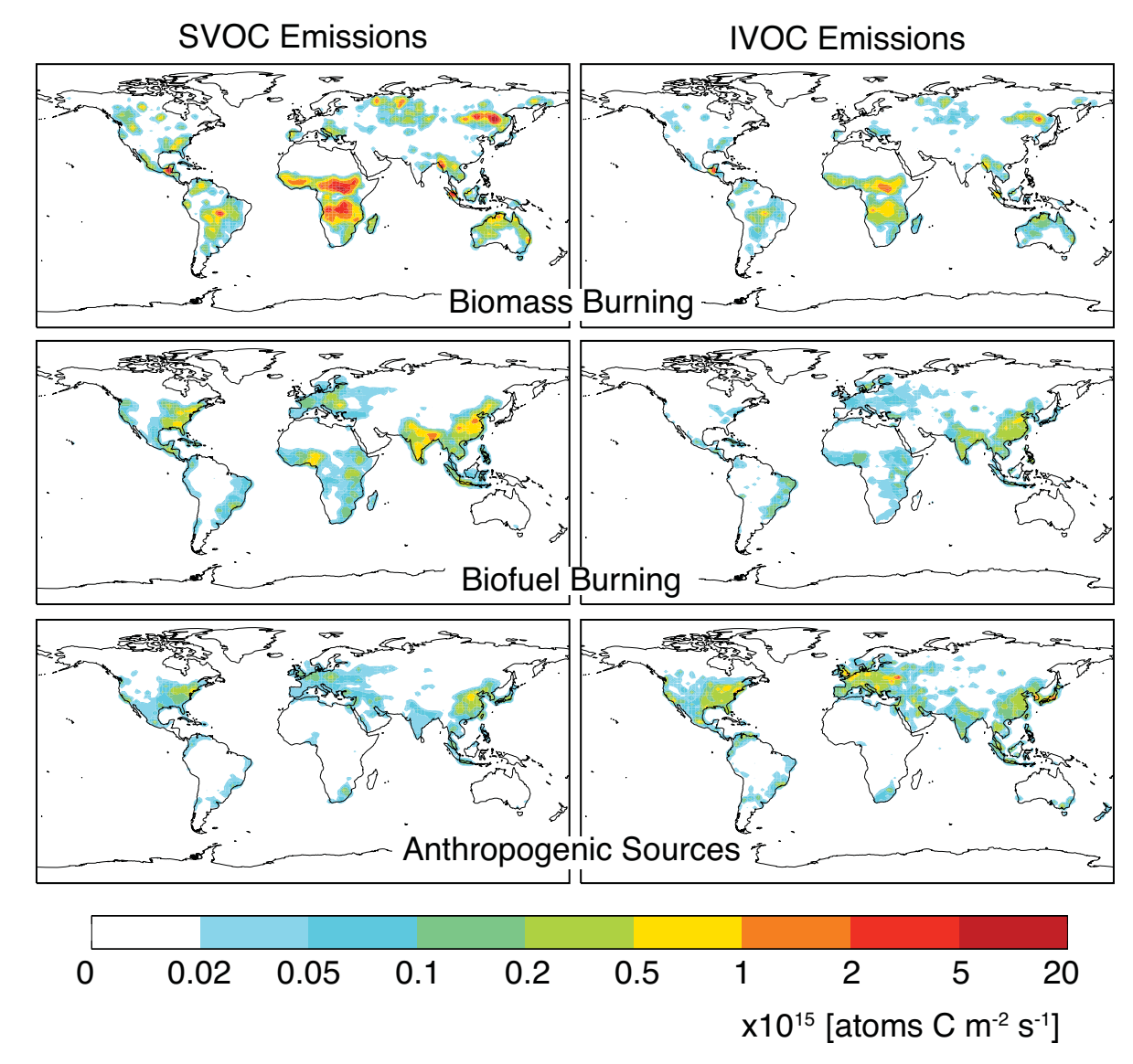

Fig. 1. Emissions of SVOCs and IVOCs. SVOC emissions shown here are the baseline POA emission inventory. Plots are annual averages for year 2000. Note that the color scale is not linear.

The SVOC emission rate in grid cell $I, J$ can be estimated using:

$E_{\mathrm{SVOC}}(I, J)=\left[1+\frac{\mathrm{G}_{\mathrm{R}}}{\mathrm{POA}_{\mathrm{R}}}\right] E_{\mathrm{NVPOA}}(I, J)$

where $E_{\mathrm{SVOC}}$ is the emission rate of SVOCs (Tg C/yr), $G_{R}$ is the emission of the gas-phase SVOC surrogate in a representative study $(\mathrm{mg} / \mathrm{kg}), \mathrm{POA}_{\mathrm{R}}$ is the emission of organic aerosol in that same representative study $(\mathrm{mg} / \mathrm{kg})$, and $\mathrm{E}_{\mathrm{NVPOA}}$ is the traditional, non-volatile POA emission rate ( $\mathrm{Tg} \mathrm{C} / \mathrm{yr}$ ). For unit conversion purposes, the organic matter to organic carbon $(\mathrm{OM} / \mathrm{OC})$ ratio is assumed to be the same for $G_{R}$ and $P O A_{R}$ in the above equation. Using the work of Schauer et al. (2001) as the representative study, the ratio of gas-phase SVOC surrogates to the particle-phase organics $\left(\mathrm{G}_{\mathrm{R}} / \mathrm{POA}_{\mathrm{R}}\right)$ is about 0.27 . The gas-phase SVOC surrogate estimate is based on adding up the gas-phase speciated emissions that were also found in the particle phase. Some of the SVOC emissions could be part of the gas-phase unresolved complex mixture in the work of Schauer et al. (2001) or were misclassified as IVOCs and are not reflected in the 0.27 estimate. Accounting for all the gas-phase species on the PUF sampling train/filter and the entire gas-phase UCM would increase the 0.27 estimate to 0.61 . The possibility remains that POA inventories may represent a significantly 
different fraction of SVOCs than in the study of Schauer et al. (2001), and scaling POA emissions up $27 \%$ is likely a fairly conservative estimate, given that the uncertainty in the baseline POA emissions is easily a factor of 2 (Bond et al., 2004). Global emissions of SVOCs are predicted to be $37 \mathrm{Tg} \mathrm{C} \mathrm{yr}^{-1}$ (Table 2 and Fig. 1).

Since traditional POA inventories are reported as the mass of carbon emitted, the mass of organic matter that includes any additional oxygen, nitrogen, or other species associated with the carbon must be determined. The range of OM/OC ratios for SVOCs likely ranges from just above 1 for carbonrich species to above 2 for highly oxygenated species such as those found in wood smoke (Schauer et al., 2001). Simulations here use a value of 1.4 , which is only slightly higher than the $\mathrm{OM} / \mathrm{OC}$ ratio estimated for hydrocarbon like organic aerosol, HOA (OM/OC: 1.2-1.3) (Aiken et al., 2008; Zhang et al., 2005), slightly lower then the OM/OC ratio for primary biomass burning organic aerosol, P-BBOA (OM/OC: 1.6-1.7) (Aiken et al., 2008), and consistent with the wood burning inventory of Schauer et al. (2001) (OM/OC: 1.41.7). The $\mathrm{OM} / \mathrm{OC}$ ratio affects the partitioning of organics since it determines the total SVOC mass available for partitioning.

\subsubsection{SVOC oxidation}

Primary SVOC emissions age in the gas phase by reaction with $\mathrm{OH}$, based on the wood burning chamber experiments of Grieshop et al. (2009a). An $\mathrm{OH}$ rate constant of $2 \times 10^{-11} \mathrm{~cm}^{3} / \mathrm{molec} / \mathrm{s}$ is assumed for the present work. The mass of the parent SVOC is assumed to increase 50\% through functionalization, a value slightly larger than, but still consistent with, Grieshop et al. (2009a) for oxidation of wood smoke. The volatility of the SVOC is reduced by a factor of 100 as a result of the $\mathrm{OH}$ reaction. This represents a slightly slower rate of oxidation, but a more aggressive addition of oxygen and reduction in volatility, than that used by Robinson et al. (2007) and was found to give better O:C ratio agreement with experiments than the traditional Robinson et al. (2007) parameters in the work of Grieshop et al. (2009a). Table 3 summarizes the SVOC oxidation parameters and compares them with the optimized parameters in the work of Grieshop et al. (2009a) and the parameters of Robinson et al. (2007).

The mechanism by which aging of low-volatility organic compounds occurs is not well-constrained. Previous work (Robinson et al., 2007) has suggested that aging occurs as the result of sequential $\mathrm{OH}$ oxidation reactions in the gasphase. The SVOCs in the present study are assumed to undergo only one generation of oxidation. This assumption is made for three main reasons. First, chamber studies, which are the source of oxidation data, tend to access only initial reactions. Secondly, since the model assumes that oxidation leads only to functionalization of the molecule and therefore a reduction in volatility, it is likely to be less valid for later generations of oxidation in which molecular fragmentation becomes more important (Kroll et al., 2009). Lastly, for a $50 \%$ (or $40 \%$ as used by Grieshop et al., 2009a) increase in mass per generation, a parent SVOC with an initial $\mathrm{OM} / \mathrm{OC}$ of 1.4 would require only 1 generation of oxidation to reach a final $\mathrm{OM} / \mathrm{OC}$ of about 2 , consistent with the observed OM/OC of aged aerosol in the experiment on which the parameters are based (Grieshop et al., 2009a), with the OM/OC of oxygenated organic aerosol, OOA (OM/OC: 1.82.4, 2.2) (Aiken et al., 2008; Zhang et al., 2005), and with other estimates of the OM/OC of oxidized regional aerosol (OM/OC: 2.1) (Turpin and Lim, 2001).

\subsection{Aerosol from IVOCs}

IVOCs are emitted entirely in the gas phase and form aerosol only upon oxidation. Since naphthalene is predicted to be a major SOA precursor in the oxidation of wood burning and diesel combustion exhaust (Chan et al., 2009), here, IVOCs are represented as a naphthalene-like surrogate that forms aerosol according to the chamber studies of Chan et al. (2009).

In addition to naphthalene, other important classes of speciated IVOCs include alkanes and phenols (Schauer et al., 2001, 2002). A significant portion of IVOCs likely belong to the unresolved complex mixture and thus their identity and aerosol yield is not known. Aerosol yield information is available for many alkanes (Jordan et al., 2008) as well as naphthalene and functionalized naphthalene species (Chan et al., 2009). Gasoline combustion likely produces more alkanes than aromatics (Schauer et al., 2002), but wood burning, globally the largest source of POA, likely emits more gas-phase aromatics than alkanes (Schauer et al., 2001; Hays et al., 2002). Approximately $75 \%$ of the speciated IVOC surrogate in the wood burning inventory of Schauer et al. (2001) is phenol $\left(C^{*}\right.$ about $\left.10^{6} \mu \mathrm{g} / \mathrm{m}^{3}\right)$ or substituted phenol compounds. Due to their ring structures, these phenol compounds are likely to behave more like naphthalene than an alkane in terms of yields under high- $\mathrm{NO}_{\mathrm{x}}$ vs. low- $\mathrm{NO}_{\mathrm{x}}$ conditions. So, if all IVOCs are to be represented with one surrogate compound, naphthalene is a good choice.

\subsubsection{IVOC emissions}

Since naphthalene is an important IVOC from many sources including wood combustion and vehicle exhaust (Chan et al., 2009; Schauer et al., 2001, 2002), IVOC emissions are assumed to be spatially distributed like naphthalene. First, a baseline emission inventory of naphthalene (NAP) is created. For biomass and biofuel burning, this is done using an emission ratio to $\mathrm{CO}$. An emission factor of $0.025 \mathrm{~g} \mathrm{NAP} / \mathrm{kg}$ dry matter burned is used along with $\mathrm{CO}$ emission factors (Andreae and Merlet, 2001) to produce emission ratios of 0.0602 and $0.0701 \mathrm{mmol} \mathrm{NAP} / \mathrm{mol} \mathrm{CO}$ for biomass and biofuel burning, respectively. The emission factor presented by 
Andreae and Merlet (2001) is consistent with that of naphthalene presented by Hays et al. (2002) for the burning of foliar fuels, but about a factor of 10 lower than the value in the work of Schauer et al. (2001). Anthropogenic naphthalene emissions, from sources such as traffic oil combustion, consumer products, and industrial sources (Zhang and Tao, 2009), are spatially distributed like benzene from the EDGAR2 inventory and are aseasonal. Emissions given for 1990 are scaled to year 2000 based on $\mathrm{CO}_{2}$ emissions from liquid fossil fuel usage (Bey et al., 2001; Fu et al., 2008). The magnitude of non-biomass and biofuel burning emissions of naphthalene is estimated based on Zhang and Tao (2009) to be about $0.09 \mathrm{Tg} \mathrm{C} / \mathrm{yr}$. The baseline naphthalene emission inventory from all sources constructed here is approximately $0.22 \mathrm{Tg} \mathrm{C} / \mathrm{yr}$ (Table 2).

As is the case for SVOCs, the magnitude of total IVOC emissions is uncertain. To estimate total IVOC emissions, the naphthalene emission inventory is scaled up. This assumes that the relative contributions of biomass burning vs. biofuel burning vs. anthropogenic sources to IVOC emissions are consistent with those of naphthalene. The emission rate of IVOCs in grid cell $I, J$ ( $\left.E_{\mathrm{IVOC}}\right)$ is determined by scaling the naphthalene emission $\left(E_{\mathrm{NAP}}\right)$,

$E_{\mathrm{IVOC}}(I, J)=\beta E_{\mathrm{NAP}}(I, J)$

where, the scaling factor, $\beta$, is estimated from,

$\beta=E_{\mathrm{NVPOA}, \mathrm{BB}+\mathrm{BF}}$

$\left(\frac{E_{\mathrm{IVOC}, \mathrm{BB}+\mathrm{BF}}}{E_{\mathrm{NVPOA}, \mathrm{BB}+\mathrm{BF}}}\right)_{\mathrm{R}_{1}}\left(\frac{E_{\mathrm{IVOC}, \mathrm{TOT}}}{E_{\mathrm{IVOC}, \mathrm{BB}+\mathrm{BF}}}\right)_{\mathrm{R}_{2}}\left(\frac{1}{E_{\mathrm{NAP}, \mathrm{TOT}}}\right)$

$E_{A, B}$ are the global emissions of species $A$ (IVOC, NVPOA: traditional POA, or NAP: naphthalene) from source type $B$ (BB: biomass burning, BF: biofuel burning, or TOT: total). Subscripts $R_{1}$ and $R_{2}$ are used to label the two ratios for further discussion.

The first ratio in Eq. (9), $R_{1}$, is estimated based on the Schauer et al. (2001) inventory for pine wood burning. $E_{\mathrm{IVOC}, \mathrm{BB}+\mathrm{BF}}$ is approximated as any species collected on the filter/polyurethane foam (PUF) sampling train with only a gas-phase emission reported plus the entire gas-phase unresolved complex mixture (UCM). The gas-phase UCM in the work of Schauer et al. (2001) for pine wood burning represents roughly $10 \%$ of the total non-methane organic carbon (gas+aerosol) mass emitted. The two contributions (PUF gases and UCM gases) to IVOC emissions are roughly equal. Using the organic aerosol emission rate $\left(E_{\mathrm{NVPOA}, \mathrm{BB}+\mathrm{BF}}\right)$ from the work of Schauer et al. (2001) as well, $\mathrm{R}_{1}$ is estimated as,

$$
\frac{E_{\mathrm{IVOC}, \mathrm{BB}+\mathrm{BF}}}{E_{\mathrm{NVPOA}, \mathrm{BB}+\mathrm{BF}}} \approx 0.34 \text {. }
$$

Since the IVOC is spatially distributed like naphthalene, $\mathrm{R}_{2}$ can be replaced by:

$$
\frac{E_{\mathrm{IVOC}, \mathrm{TOT}}}{E_{\mathrm{IVOC}, \mathrm{BB}+\mathrm{BF}}}=\frac{E_{\mathrm{NAP}, \mathrm{TOT}}}{E_{\mathrm{NAP}, \mathrm{BB}+\mathrm{BF}}}
$$

and consequently, only $E_{\mathrm{NAP}, \mathrm{BB}+\mathrm{BF}}$ is needed to complete the scaling factor.

Thus, our scaling incorporates two ideas: IVOCs are spatially distributed like naphthalene and the ratio of IVOCs to traditional POA for wood burning sources is 0.34 as in the work of Schauer et al. (2001). As a result, the predicted scaling factor, $\beta$, is 66 and yields a global IVOC emission rate of about $15 \mathrm{TgC} / \mathrm{yr}$ (Table 2 and Fig. 1). The large value of the scaling factor, $\beta$, means that naphthalene itself is actually a relatively small $(<2 \%)$ contribution to global IVOC emissions.

The IVOC emissions are not linked to the POA emission inventory within each grid cell; rather, they are spatially distributed like naphthalene. On a global basis, the present work predicts IVOC emissions of roughly $0.5 \times \mathrm{POA}$ in magnitude. As a result of the separation of POA and IVOC emissions, the ratio of IVOC:traditional POA emissions is roughly 2.1 for anthropogenic sources and 0.34 for biomass and biofuel sources combined. These ratios are consistent with the discussion by Shrivastava et al. (2008) and box model studies by Grieshop et al. (2009a), indicating that diesel combustion (an anthropogenic source) may produce relatively more IVOCs than wood burning.

\subsubsection{IVOC oxidation}

IVOC aging behavior is based on the chamber studies of Chan et al. (2009) and Kautzman et al. (2010) examining the oxidation of naphthalene under high- and low- $\mathrm{NO}_{\mathrm{x}}$ conditions. Similar to light aromatic oxidation (Ng et al., 2007), naphthalene oxidation under high- $\mathrm{NO}_{\mathrm{x}}$ conditions was found to produce semivolatile SOA while oxidation under low- $\mathrm{NO}_{\mathrm{x}}$ conditions was found to produce essentially non-volatile SOA. The yield of aerosol ranged from 13 to $30 \%$ for the high- $\mathrm{NO}_{\mathrm{x}}$ oxidation and was constant at $73 \%$ for low- $\mathrm{NO}_{\mathrm{x}}$ oxidation. For naphthalene, the results indicate that the first oxidation step is rate-limiting for SOA formation. Calculations using diesel engine and wood burning emission profiles indicate that naphthalene and other PAHs are responsible for substantially more SOA than light aromatics on short timescales (about 12 h) (Chan et al., 2009), and ambient aerosol contains compounds indicative of naphthalene oxidation (Kautzman et al., 2010).

Formation of aerosol from IVOC oxidation is modeled similar to the aerosol from aromatic oxidation in the work of Henze et al. (2008). Reaction of the parent hydrocarbon with $\mathrm{OH}$ in the presence of oxygen results in the formation of a peroxy radical species,

Naphthalene $+\mathrm{OH} \rightarrow \mathrm{RO}_{2}$

Under high- $\mathrm{NO}_{\mathrm{x}}$ conditions, reaction of the $\mathrm{RO}_{2}$ radical with $\mathrm{NO}$ likely dominates over reaction of $\mathrm{RO}_{2}$ with $\mathrm{HO}_{2}$ or $\mathrm{RO}_{2}$ and thus SOA can be assumed to form from the following channel:

$\mathrm{RO}_{2}+\mathrm{NO} \rightarrow \alpha_{N, 1} \mathrm{P}_{\mathrm{N}, 1}+\alpha_{N, 2} \mathrm{P}_{\mathrm{N}, 2}$ 
Table 4. Rate constants for IVOC oxidation. $k=A \mathrm{e}^{B / T}$.

\begin{tabular}{|c|c|c|c|}
\hline Reaction & $\begin{array}{c}A \\
{\left[\mathrm{~cm}^{3} \text { molec }^{-1} \mathrm{~s}^{-1}\right]}\end{array}$ & $\begin{array}{c}B \\
{[\mathrm{~K}]}\end{array}$ & $\begin{array}{c}k_{298} \\
{\left[\mathrm{~cm}^{3} \mathrm{molec}^{-1} \mathrm{~s}^{-1}\right]}\end{array}$ \\
\hline $\mathrm{NAP}+\mathrm{OH}$ & $1.56 \times 10^{-11}$ & 117 & $2.3 \times 10^{-11}$ \\
\hline $\mathrm{RO}_{2}+\mathrm{HO}_{2}$ & $1.4 \times 10^{-12}$ & 700 & $1.5 \times 10^{-11}$ \\
\hline $\mathrm{RO}_{2}+\mathrm{NO}$ & $2.6 \times 10^{-12}$ & 350 & $8.5 \times 10^{-12}$ \\
\hline
\end{tabular}

Sources: Atkinson and Arey (2003); Henze et al. (2008); Atkinson (1997)

where the two semivolatile products are described using parameters by Chan et al. (2009). Under low- $\mathrm{NO}_{\mathrm{x}}$ conditions, the $\mathrm{RO}_{2}$ radical is expected to react predominantly with $\mathrm{HO}_{2}$ and lead to one essentially non-volatile product (Chan et al., 2009; Kautzman et al., 2010):

$\mathrm{RO}_{2}+\mathrm{HO}_{2} \rightarrow \alpha_{H, 1} \mathrm{P}_{\mathrm{H}, 1}$

In practice, the non-volatile SOA product is represented in GEOS-Chem using a partitioning coefficient, $K_{\mathrm{OM}}$, of $10^{4} \mathrm{~m}^{3} / \mu \mathrm{g}$. Values for the partitioning coefficients and massbased stoichiometric coefficients of all the products are given in Table 1 , and Table 4 contains the gas-phase rate constants.

\subsection{Additional model parameters and specifications}

In the current version of GEOS-Chem, the semivolatile products of parent hydrocarbon oxidation are lumped together into several gas-phase and aerosol-phase tracers (Henze and Seinfeld, 2006; Liao et al., 2007; Henze et al., 2008). Since the identity of each individual species is not preserved during transport, some artificial migration of mass between the volatilities may occur. In the present work, for the SVOC related species, separate tracers are used for each phase (gas and aerosol) as well as each volatility for a total of 4 tracers related to primary SVOC emissions and 4 tracers for SVOC oxidation products. The use of separate tracers prevents migration between the different volatilities during transport which was found to be significant at $4^{\circ} \times 5^{\circ}$ resolution using a lumped tracer. For IVOC oxidation, the effects of lumping were found to be less significant, but in order to obtain the best estimate of IVOC aerosol produced under high- $\mathrm{NO}_{\mathrm{x}}$ conditions, separate tracers for each of the IVOC oxidation products are used. Each species with a saturation concentration below $10^{5} \mu \mathrm{g} / \mathrm{m}^{3}$ in Table 1 has a separate gas and aerosol phase tracer. The IVOC has a gas-phase tracer only for a total of 15 additional tracers for the low-volatility organic aerosol simulation. A list of GEOS-Chem tracers for a standard full-chemistry SOA simulation can be found in Table 2 in the work of Liao et al. (2007).

Emitted SVOCs, aged SVOCs, and aged IVOCs in the gas and aerosol phases are subject to wet and dry deposition. The IVOC surrogate gas is not deposited. Dry deposition is represented by a resistance in series method (We- sely, 1989), with the surface resistances for aerosols following the work of Zhang et al. (2001). SVOCs that partition directly to the aerosol phase to form POA are treated as hydrophobic and are assumed insoluble. Gas-phase SVOC emissions are treated as relatively hydrophobic with an effective Henry's law coefficient of $9.5 \mathrm{M} / \mathrm{atm}$ and a heat of dissolution, $\Delta H / R$ of $-4700 \mathrm{~K}$ based on phenanthrene (Sander, 1999). Other SVOC species, such as long-chain alkanes, are more hydrophobic with Henry's law coefficients of $10^{-4} \mathrm{M} / \mathrm{atm}$ to $0.3 \mathrm{M} / \mathrm{atm}$. However, SVOCs such as functionalized phenols or oxygenated species, will likely be more soluble than phenanthrene. The SVOC and IVOC oxidation products are treated like the traditional SOA species and are hydrophilic (Henry's law coefficient of $10^{5} \mathrm{M} / \mathrm{atm}$ for all gasphase semivolatiles), and all SOA is scavenged with an $80 \%$ efficiency (Chung and Seinfeld, 2002). The effect of a lower Henry's law coefficient will be examined in sensitivity studies.

The equilibrium partitioning coefficients of all species are adjusted for temperature based on the Clausius-Clapeyron equation. As in previous studies using GEOS-Chem, the enthalpy of vaporization is assumed to be $42 \mathrm{~kJ} / \mathrm{mol}$ for all organic species (Chung and Seinfeld, 2002). However, a discrepancy exists in the predicted enthalpy of vaporization for semivolatile organic aerosol estimated for complex SOA systems (around 10-40 kJ/mol, Offenberg et al. (2006)) and based on theory or single component systems (around $100 \mathrm{~kJ} / \mathrm{mol}$, Epstein et al. (2010)). The enthalpy of vaporization is examined in Sect. 3.4.1.

\subsection{Aerosol aging}

Modeling efforts are still limited in their ability to represent aging that occurs on timescales longer than a few days, as these conditions are not readily accessed in chamber experiments (Jimenez et al., 2009). On long timescales, compounds may continue to functionalize and form more aerosol or may fragment and reduce aerosol formation. Chamber experiments tend to produce aerosol that resembles semivolatile oxygenated OA, SV-OOA, which is higher in volatility and lower in $\mathrm{O}: \mathrm{C}$ than that observed in the atmosphere which tends to be dominated by low-volatility oxygenated OA, LVOOA, with high O:C (Ng et al., 2009). Lane et al. (2008), Murphy and Pandis (2009), Jimenez et al. (2009), and Farina et al. (2010) have postulated that the semivolatiles formed from traditional precursors such as isoprene, terpenes, and aromatics continue to oxidize in the atmosphere in the gas phase. However, the analysis of Chhabra et al. (2010) indicates that the chamber oxidation of several parent hydrocarbons, including toluene, xylene, and naphthalene, does approach LV-OOA type aerosol with high O:C. In the work presented here, chemical reaction and aerosol formation from all parent hydrocarbons (traditional, SVOCs, and IVOCs) is limited to the behavior that is currently captured in chamber experiments. 

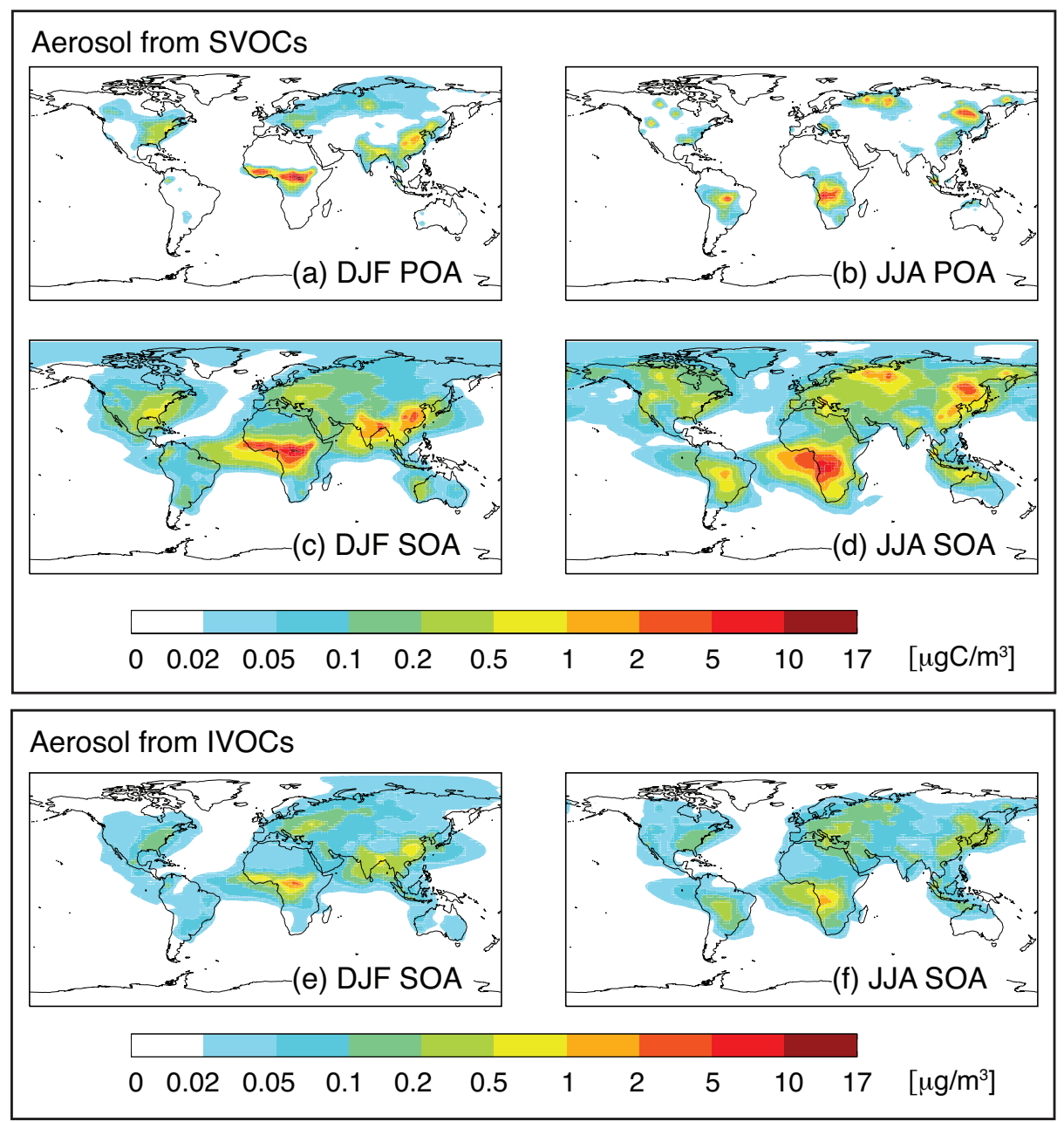

Fig. 2. Predicted concentration of aerosol from SVOCs and IVOCs. Aerosol from SVOCs includes POA, (a and b), and SOA, (c and d), and is expressed in $\mu \mathrm{g} \mathrm{C} / \mathrm{m}^{3}$. Aerosol from IVOCs is shown in panels (e and $\mathbf{f}$ ) and is expressed in $\mu \mathrm{g} / \mathrm{m}^{3}$. Concentrations are shown at the surface for December-January-February (DJF) and June-July-August (JJA) for year $2000\left(\right.$ GEOS- $\left.4,2^{\circ} \times 2.5^{\circ}\right)$. Note that the color scale is not linear.

\section{Results and discussion}

\subsection{OA from SVOCs and IVOCs}

Figure 2 shows the amount of organic aerosol predicted to form from direct partitioning of SVOC emissions (POA), oxidation of SVOCs, and oxidation of IVOCs. Concentrations are shown for the winter and summer at the surface. The highest POA concentrations (Fig. 2a, b) reflect biomass burning source regions, but anthropogenic source regions such as the US and East Asia also have high POA concentrations. Compared to POA, the SOA formed from SVOC oxidation is more regionally distributed (Fig. 2c, d). SOA from IVOC oxidation has a similar spatial distribution to SOA from SVOCs, but in general, concentrations are lower (Fig. 2e, f).
Compared to the traditional simulation with nonvolatile POA and no IVOCs, generally less total organic aerosol is predicted at the surface in the revised simulation with semivolatile POA, primary SVOC aging in the gas phase, and SOA from IVOCs (see Fig. S1 in supplement (http://www.atmos-chem-phys.net/10/4377/ 2010/acp-10-4377-2010-supplement.pdf), note that both traditional and revised simulations form aerosol from traditional SOA precursors such as biogenic hydrocarbons and light aromatics). The largest decreases in total organic aerosol are over the biomass burning and isoprene source regions. Small increases of up to $0.2 \mu \mathrm{g} / \mathrm{m}^{3}$ in organic aerosol are predicted at northern high latitudes in DJF (December-January-February). The largest surface level, seasonally averaged increase $\left(0.4 \mu \mathrm{g} / \mathrm{m}^{3}\right)$ occurs during SON (September-October-November) over Eastern Russia near a 
Fraction of primary SVOC in particle phase
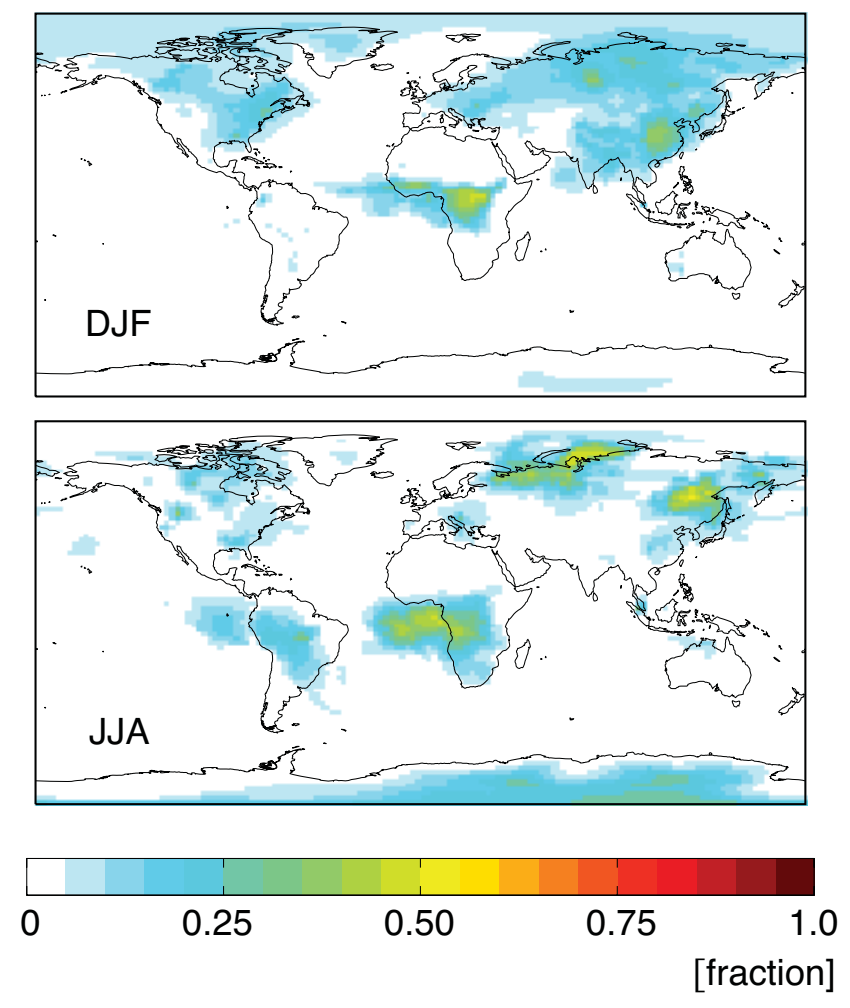

Fig. 3. Fraction of primary semivolatile material in aerosol phase as POA at the surface, seasonally averaged for year 2000. Fraction is simply the aerosol-phase SVOC concentrations (in ppb) divided by the total SVOC (gas+aerosol) concentration (in ppb). Simulations performed with GEOS -4 at $2^{\circ} \times 2.5^{\circ}$.

biomass burning source region as a result of IVOC oxidation.

While the revised simulation generally predicts lower total OA concentrations near the surface, starting at roughly $4 \mathrm{~km}$ (model level 7) OA concentrations tend to be higher in the revised simulation (Fig. S1). Not all regional changes necessarily transition from decreases to increases at $4 \mathrm{~km}$ though. Concentrations over the US during JJA (June-July-August) tend to be lower than the traditional simulation predicts up until about $7 \mathrm{~km}$. Biomass burning outflow (JJA Africa), South American outflow (JJA and SON), and Asian outflow regions are among the first locations other than high latitudes at which increases in total OA occur as altitude increases.

Several factors influence the change in organic aerosol concentration between the traditional and revised simulations. With semivolatile POA, concentrations will tend to decrease, as a large portion of the POA is predicted to evaporate. The SVOC emission rate is higher (27\%) than the standard POA emission rate, but not high enough to compensate for POA evaporation. This shift to the gas phase is reflected in Fig. 3, which displays the fraction of primary SVOCs in the particle phase as POA in the revised simulation. During DJF over the eastern US, about $20 \%$ and as much as $27 \%$ of

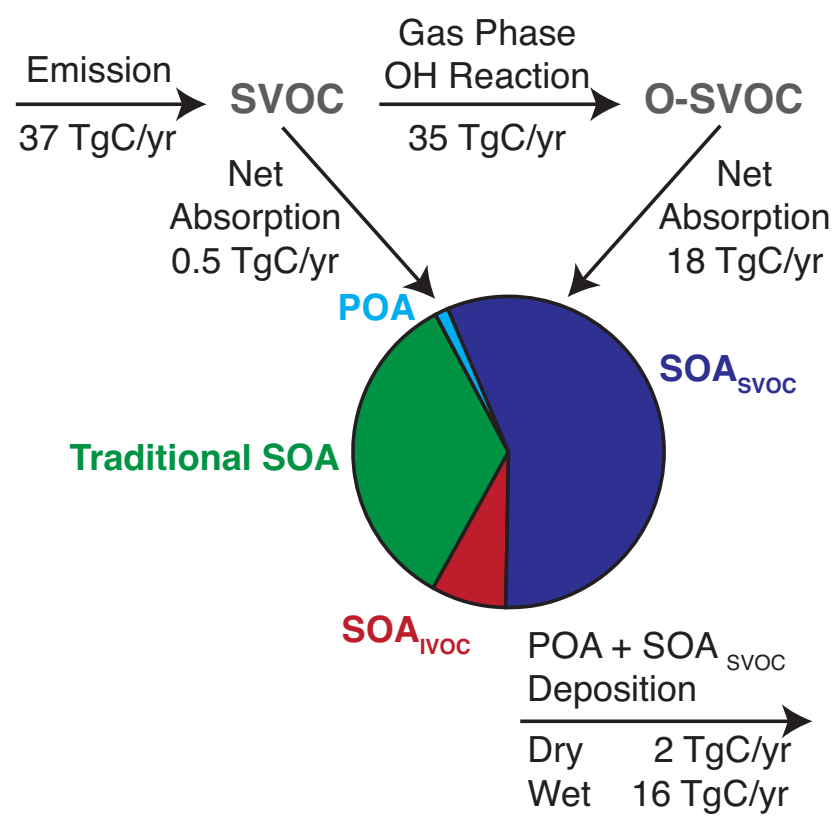

Fig. 4. SVOC budget. Relative portions of pie indicate annual net production (32 Tg C/yr total). SVOC and O-SVOC (oxidized SVOC) are also wet and dry deposited (not shown). All numbers are for year 2000 . Simulation performed at $2^{\circ} \times 2.5^{\circ}$ with GEOS-4 meteorology.

the primary SVOC is partitioned to the aerosol phase. (At $270 \mathrm{~K}$, a typical wintertime temperature in the Northeast US, the saturation concentration of $\mathrm{SVOC}_{2}$ is about $3 \mu \mathrm{g} / \mathrm{m}^{3}$.) In $\mathrm{JJA}, 10$ to $20 \%$ of the SVOC is in the aerosol phase. In the western US as much as $36 \%$ is in the particle phase due to high biomass burning emissions. In addition to the effect of evaporation, the OM/OC ratio for POA decreases from 2.1 in the traditional simulation to 1.4 in the revised simulation, which affects the amount of aerosol available for partitioning.

Concentrations of total OA could also increase for a number of reasons. Since SVOCs are oxidized in the gas phase, OA will tend to be shifted toward more remote or downwind areas relative to source regions. Also, changes in wet deposition (SVOCs and oxidized SVOCs are less aggressively wet deposited than hydrophilic traditional POA) allow further transport of some SVOC emissions. The introduction of IVOCs adds another source of OA. Oxidation of the IVOC through the $\mathrm{RO}_{2}+\mathrm{HO}_{2}$ route (which is more dominant than the $\mathrm{RO}_{2}+\mathrm{NO}$ route in remote regions, Henze et al., 2008) produces non-volatile aerosol at a high yield. Still, even with the introduction of IVOCs, surface OA levels are lower than those in the traditional model (Fig. S1, http://www.atmos-chem-phys.net/10/4377/ 2010/acp-10-4377-2010-supplement.pdf). 
Table 5. Global OA budget for traditional (non-volatile POA) and revised (semivolatile POA, SOA from SVOCs, and SOA from IVOCs) simulations. The OM/OC ratio for traditional, non-volatile POA is 2.1. The OM/OC ratio for semivolatile POA is 1.4 . The OM/OC ratio for all SOA is 2.1 . Simulations were performed at $2^{\circ} \times 2.5^{\circ}$ horizontal resolution with GEOS-4 meteorology.

\begin{tabular}{lccccc}
\hline & $\begin{array}{c}\text { Tropospheric } \\
\text { burden } \\
{[\mathrm{Tg}]}\end{array}$ & $\begin{array}{c}\text { Net } \\
\text { Source } \\
{[\mathrm{Tg} / \mathrm{yr}]}\end{array}$ & $\begin{array}{c}\text { Wet } \\
\text { Deposition } \\
{[\mathrm{Tg} / \mathrm{yr}]}\end{array}$ & $\begin{array}{c}\text { Dry } \\
\text { Deposition } \\
{[\mathrm{Tg} / \mathrm{yr}]}\end{array}$ & $\begin{array}{c}\text { Lifetime } \\
{[\text { days] }}\end{array}$ \\
\hline $\begin{array}{l}\text { Traditional Non-volatile POA Simulation } \\
\text { Traditional POA }\end{array}$ & 0.92 & 61 & 53 & 8.4 & 5.5 \\
$\quad$ Traditional SOA & 0.72 & 26 & 23 & 2.3 & 10 \\
$\quad$ Total OA & 1.64 & 87 & 76 & 11 & 6.9 \\
$\quad$ Revised Simulation & & & & & \\
$\quad$ Semivolatile POA & 0.03 & 0.70 & 0.22 & 0.49 & 17 \\
$\quad$ SOA from SVOCs & 0.81 & 38 & 34 & 4.4 & 7.7 \\
SOA from IVOCs & 0.09 & 5.2 & 4.6 & 0.6 & 6.5 \\
$\quad$ Traditional SOA & 0.71 & 23 & 21 & 2.0 & 11 \\
$\quad$ Total OA & 1.65 & 67 & 60 & 7.4 & 9.0 \\
Percent Change in OA & & & & & \\
$\quad$ Traditional OA & $-1 \%$ & $-11 \%$ & $-11 \%$ & $-15 \%$ & $12 \%$ \\
$\quad$ Total OA & $0 \%$ & $-23 \%$ & $-22 \%$ & $-31 \%$ & $30 \%$ \\
\hline
\end{tabular}

a Net Source includes emission for POA in the traditional simulation.

\subsection{Global budgets}

Despite the fact that the revised simulation, with the new SVOC and IVOC inventories, has a larger pool of organics with the potential to form OA, global production of OA decreases $23 \%$ in the revised simulation compared to the traditional simulation. Table 5 shows the global OA budget for each simulation. In the traditional simulation, traditional SOA and non-volatile POA represent a global OA source of $87 \mathrm{Tg} / \mathrm{yr}$. In the revised simulation, the net OA source decreases to $67 \mathrm{Tg} / \mathrm{yr}$. The formation of traditional SOA decreases as well (although only 11\%), likely as a result of a reduced partitioning medium into which the SOA may absorb. The tropospheric lifetime of OA against deposition (defined as the tropospheric burden divided by the sum of wet and dry deposition) increases in the revised simulation. In the traditional simulation, POA is assumed to be emitted as 50\% hydrophobic and $50 \%$ hydrophilic and converted from hydrophobic to hydrophilic forms with an e-folding lifetime of 1.15 days. In the revised simulation, the hydrophobic nature of POA leads to a much longer POA lifetime (17 days against deposition). In addition, production of aerosol is shifted to higher altitudes where it is less subject to wet or dry deposition and thus has a longer lifetime. By coincidence, the global tropospheric burden of organic aerosol is roughly the same in the traditional and revised simulations.

As shown in Fig. 4, only about $50 \%$ of the carbon emitted as an SVOC leads to net aerosol production. The rest is wet or dry deposited in the gas phase. Of the $37 \mathrm{Tg} \mathrm{C} / \mathrm{yr}$ emitted, only $0.5 \mathrm{Tg} \mathrm{C} / \mathrm{yr}$ are predicted to lead to net POA formation, most of which $(97 \%)$ is due to the lower volatility SVOC $\left(\mathrm{SVOC}_{2}\right) .95 \%$ of the emitted SVOC carbon reacts in the gas phase with $\mathrm{OH}$ to form an oxidized SVOC (O-SVOC). The O-SVOC is fairly effectively wet and dry deposited (it is treated like traditional gas-phase SOA products with a Henry's law coefficient of $10^{5} \mathrm{M} / \mathrm{atm}$ ) and a significant fraction is lost to deposition in the gas phase. Only $18 \mathrm{Tg} \mathrm{C} / \mathrm{yr}$ forms net SOA. Roughly $80 \%$ of the SOA from SVOCs is from the lower volatility product $\left(C^{*}=0.2 \mu \mathrm{g} / \mathrm{m}^{3}\right)$ while $20 \%$ is from the higher volatility product $\left(C^{*}=16 \mu \mathrm{g} / \mathrm{m}^{3}\right)$. Ultimately, the OA from SVOCs is lost to wet and dry deposition with wet deposition being dominant. The yield of OA from SVOCs is about $50 \%$ on a carbon basis (mass of carbon in aerosol/ mass of carbon emitted) and about $75 \%$ in terms of total mass of SVOC aerosol produced divided by total mass of SVOC emitted. Figure 4 also shows the relative rates of formation of aerosol from each source in the pie chart (in $\mathrm{Tg} \mathrm{C} / \mathrm{yr}$ ). More than half of the global aerosol carbon is predicted to come from primary SVOC oxidation products. The second largest contribution is from traditional SOA followed by SOA from IVOCs and POA.

Figure 5 shows the emission, oxidation, and SOA formation predicted for light aromatics and IVOCs. Because of where they are emitted, most of the parent hydrocarbons react following the high- $\mathrm{NO}_{\mathrm{x}} \mathrm{RO}_{2}+\mathrm{NO}$ pathway. As shown by Henze et al. (2008), aromatics that react faster with $\mathrm{OH}$ will have a greater tendency to follow the $\mathrm{RO}_{2}+\mathrm{NO}$ pathway since biofuel and fossil fuel burning emissions tend to be colocated with anthropogenic $\mathrm{NO}_{\mathrm{x}}$ sources, and the parent hydrocarbon is more likely to be oxidized in the source region. The IVOC surrogate, naphthalene, reacts faster with $\mathrm{OH}$ than benzene or toluene, but similar in rate to xylene. For both naphthalene and xylene, the amount of oxidation through the high- $\mathrm{NO}_{\mathrm{x}}$ pathway is about twice that through 
SOA Formation From Aromatics and IVOCs

$\square$ Benzene, Toluene, Xylene $\quad \square$ IVOC Surrogate

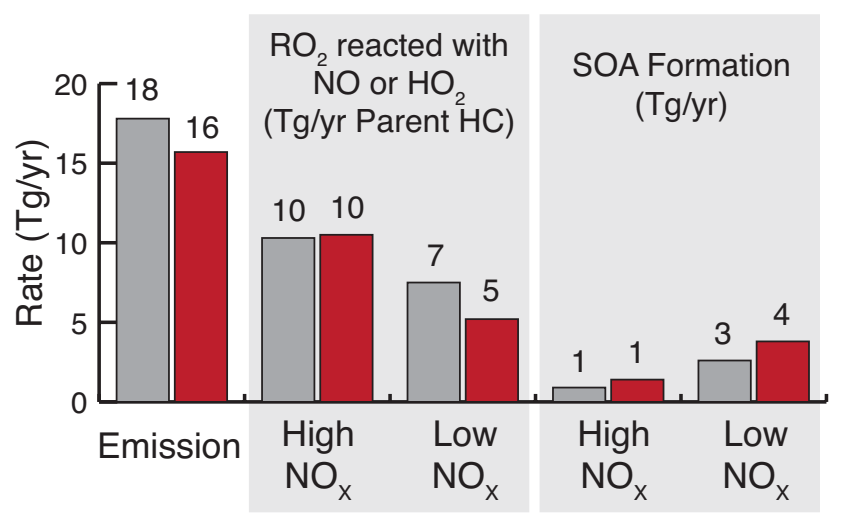

Fig. 5. Emission, oxidation, and aerosol formation from aromatics and IVOCs. Simulation performed at $2^{\circ} \times 2.5^{\circ}$ with GEOS- 4 meteorology.

the low- $\mathrm{NO}_{\mathrm{x}}$ pathway. Benzene, with the slowest $\mathrm{OH}$ rate constant, reacts slightly more through the $\mathrm{RO}_{2}+\mathrm{HO}_{2}$ than the $\mathrm{RO}_{2}+\mathrm{NO}$ pathway. The high- $\mathrm{NO}_{\mathrm{x}}$ IVOC oxidation pathway results in about $1 \mathrm{Tg} / \mathrm{yr}$ of SOA and the low- $\mathrm{NO}_{\mathrm{x}}$ pathway results in about $4 \mathrm{Tg} / \mathrm{yr}$, leading to an overall yield of aerosol from IVOCs of about $30 \%$.

\subsection{United States organic aerosol}

Figure 6 shows the predicted concentration of total OA over the United States for the winter and summer and the contributions of different OA types to that total. The contribution of light aromatics to total OA is not shown but is similar in magnitude to that from IVOCs. The highest concentrations in the winter are predicted to be located in the Southeast US as a result of a biomass burning event and high SVOC emissions. During the winter, POA is a significant contributor to total OA concentrations. POA contributions are highest in the Northeast where temperatures are lower and partitioning to the aerosol phase is favored. Anthropogenic and biofuel burning emissions also tend to be highest in the Northeast (Fig. 1). Despite significant POA contributions, SOA from SVOCs is the dominant wintertime OA component, generally contributing $50 \%$ or more to surface concentrations. In the summer, the highest OA also occurs in the Southeast, but is due primarily to biogenic SOA. The highest POA contributions in summer reflect biomass burning sources. Outside of the biomass burning locations, POA is generally lower in the summer than in the winter. Despite the significant contribution of biogenic SOA, SOA from SVOCs remains an important contributor to total OA, representing up to $50 \%$ of the OA in the Northeast and 50\% or more in the Western US.

Since the winter organic aerosol is dominated by SVOC aerosol, further examination of wintertime concentrations al- lows us to assess the model performance while minimizing uncertainties in the biogenic aerosol parameterization as a source of discrepancy. Figure 7 shows winter (DecemberJanuary-February 2000) simulated and observed aerosol OC concentrations over the US. Surface measurements of total $\mathrm{OC}$ from the Interagency Monitoring of Protected Visual Environments (IMPROVE) network (http://vista.cira.colostate. edu/improve/) are overlaid in circles on top of the simulated OC concentrations. Since the IMPROVE network observations are reported as mass of carbon rather than the mass of total organic aerosol, converting model values, which tend to be in total organic mass, to organic carbon mass is an additional source of potential discrepancy. Since the aerosol from SVOCs is tracked in GEOS-Chem as the mass of carbon and OM/OC ratios of 1.4 for POA and 2.1 for SOA are applied in the partitioning routines, focusing on the wintertime, where aerosol is dominated by SVOC sources with a model imposed OM/OC ratio, can reduce the effect of the $\mathrm{OM} / \mathrm{OC}$ ratio which must be specified for traditional and IVOC SOA. To convert traditional and IVOC SOA to OC, an $\mathrm{OM} / \mathrm{OC}$ ratio of 2.1 is used and is roughly consistent with chamber data with the notable exception of $\alpha$-pinene SOA (Chhabra et al., 2010). Comparisons to the IMPROVE network by Liao et al. (2007) indicate that GEOS-Chem underpredicts annual OA levels by about $0.56 \mu \mathrm{g} / \mathrm{m}^{3}$ (mean bias) or $34 \%$ (normalized mean bias) with the bias being larger in magnitude in the western US and lower in magnitude in the eastern US. A comparison of simulated and observed OC levels for the US during DJF 2000 in this work, indicate that GEOS-Chem underestimates OC by $0.20 \mu \mathrm{gC} / \mathrm{m}^{3}$ $(21 \%)$ for the $2^{\circ} \times 2.5^{\circ}$ simulations and $0.37 \mu \mathrm{gC} / \mathrm{m}^{3}(39 \%)$ for the $4^{\circ} \times 5^{\circ}$ simulation. The bias for the $4^{\circ} \times 5^{\circ}$ simulation is likely larger as a result of the coarser model resolution and the fact that a climatological meteorology has been used as opposed to the assimilated, year-specific meteorology used by $2^{\circ} \times 2.5^{\circ}$ simulations. Compared to the semivolatile simulation (Fig. 7 bottom), the traditional simulation (Fig. 7 top) is more consistent with the IMPROVE observations. Sensitivity tests will be used to determine the factors that allow model performance to be brought closer to observations.

\subsection{Sensitivity tests}

A number of key inputs and parameters involved in the global simulation of organic aerosol are uncertain; this fact suggests that sensitivity simulations will be useful in understanding the extent to which these uncertainties influence the predictions. The quantities examined in the sensitivity tests are listed in Table 6. For computational efficiency, the sensitivity tests are performed at $4^{\circ} \times 5^{\circ}$ resolution with GISS GCM meteorology. The effect of changes in meteorology and grid resolution on the global OA budget are examined in Appendix A. Although both the resolution and meteorology differ from those in the simulations discussed in the previous section, since the sensitivity tests address relative changes, 
Total Organic Aerosol During Winter and Summer 2000
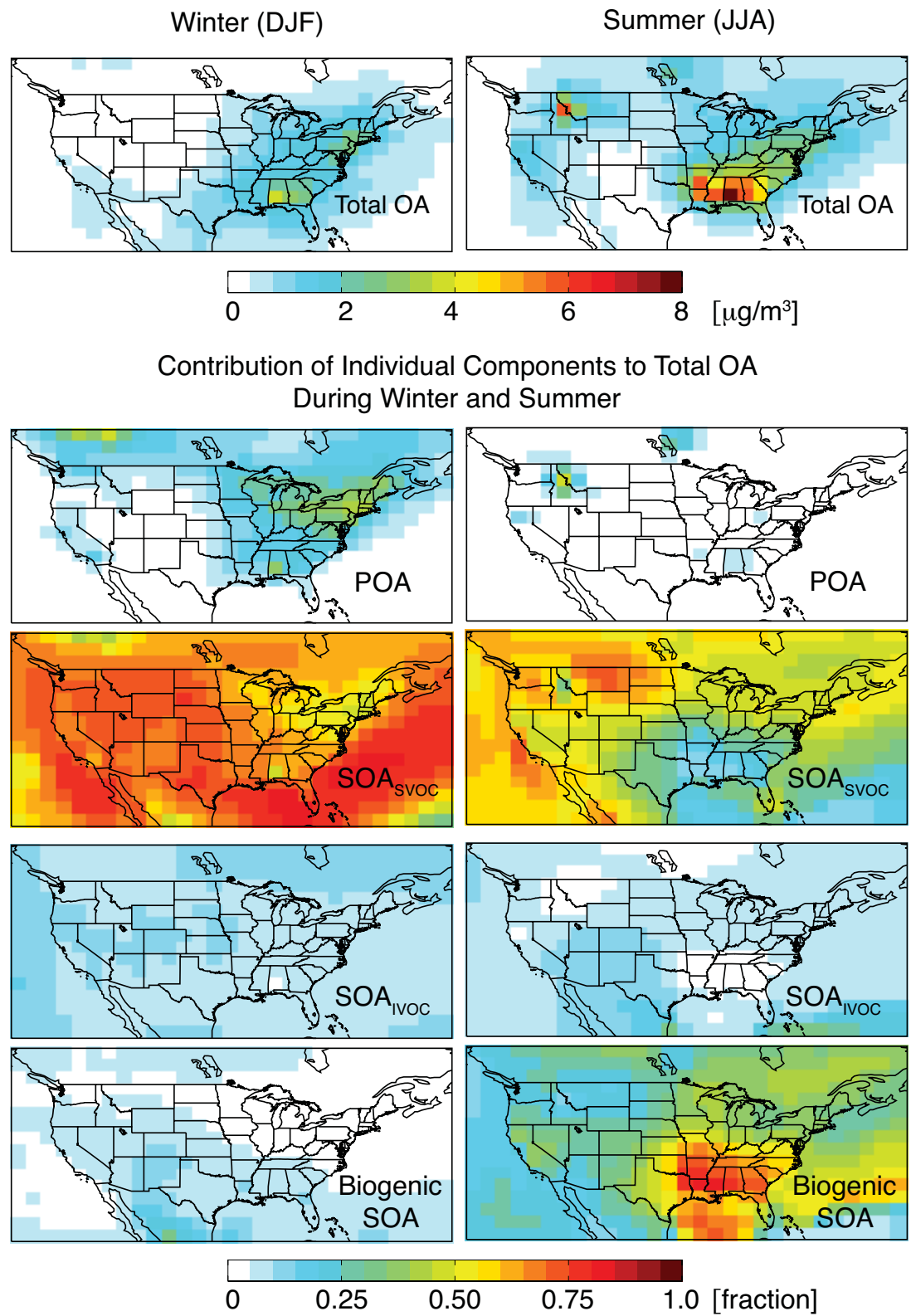

Fig. 6. Total OA and contribution of each component to winter and summer concentrations over the US. Not shown is the contribution of aromatic SOA to total OA. Fraction is fraction of total OA. Simulations are $2^{\circ} \times 2.5^{\circ}$ with GEOS-4 meteorology.

the conclusions should be robust and relatively independent of the meteorology used (a discussion of interannual variability and resolution appears in Sect. 4.3). A Traditional (nonvolatile POA and traditional SOA only) simulation is performed for comparison purposes. Even though the Revised simulation better represents the current scientific understanding of low-volatility organic compounds, the predicted concentration of OC over the US is low compared to observations (see Fig. 7). Due to the sparse nature of the IMPROVE network data for year 2000 DJF and the fact that the revised simulation predicts such low OC values, sensitivity simulations are compared to the Traditional simulation as well as observations. A traditional GEOS-Chem simulation has also been extensively evaluated against observations in the work of Liao et al. (2007).

Table 6 lists the additional simulations performed. The Revised simulation with semivolatile POA, oxidation of SVOCs, IVOC aerosol, and traditional SOA is described in previous sections. Two sensitivity tests are performed to examine the effects of changes in emissions. IVOC emissions 
Table 6. Sensitivity tests with GCM meteorology at $4^{\circ} \times 5^{\circ}$.

\begin{tabular}{|c|c|c|c|c|c|c|}
\hline Label & $\begin{array}{c}\text { IVOC Emissions } \\
\text { [Tg C/yr] }\end{array}$ & $\begin{array}{c}\text { SVOC emissions } \\
{[\mathrm{Tg} \mathrm{C} / \mathrm{yr}]}\end{array}$ & $\begin{array}{c}K_{\mathrm{OM}} \mathrm{SVOC} \\
{\left[\mathrm{m}^{3} / \mu \mathrm{g}\right]}\end{array}$ & $\begin{array}{c}K_{\mathrm{OM}} \mathrm{O}-\mathrm{SVOC} \\
{\left[\mathrm{m}^{3} / \mu \mathrm{g}\right]}\end{array}$ & $\begin{array}{c}\text { Henry's Law Coefficient }{ }^{\mathrm{c}} \\
{[\mathrm{M} / \mathrm{atm}]}\end{array}$ & $\begin{array}{c}\Delta \mathrm{H}_{\mathrm{vap}} \\
{[\mathrm{kJ} / \mathrm{mol}]}\end{array}$ \\
\hline Traditional $^{\mathrm{a}}$ & NA & 29 & large & NA & $10^{5}$ & $42^{\mathrm{d}}$ \\
\hline Revised $^{\mathrm{b}}$ & 15 & 37 & $0.0006,0.05$ & $0.06,5.0$ & Traditional & Traditional \\
\hline 2*IVOC & $2 \times$ Revised & Revised & Revised & Revised & Traditional & Traditional \\
\hline $2 * \mathrm{SVOC}$ & Revised & $2 \times$ Traditional & Revised & Revised & Traditional & Traditional \\
\hline SVOC K*10 & Revised & Revised & $10 \times$ Revised & $10 \times$ Revised & Traditional & Traditional \\
\hline O-SVOC K*10 & Revised & Revised & Revised & $10 \times$ Revised & Traditional & Traditional \\
\hline H-Law/100 & Revised & Revised & Revised & Revised & $10^{3}$ & Traditional \\
\hline$\Delta \mathrm{H}^{*} 2$ & Revised & Revised & Revised & Revised & Traditional & 83 \\
\hline
\end{tabular}

a Traditional simulation with non-volatile POA and SOA from traditional precursors.

${ }^{b}$ Revised simulation uses semivolatile POA, oxidation of SVOCs, SOA from IVOCs, and SOA from traditional precursors.

${ }^{\mathrm{c}}$ For wet removal of gas-phase semivolatiles.

$\mathrm{d}$ Implemented using a value of $41.6 \mathrm{~kJ} / \mathrm{mol}$.

\section{Winter (DJF) Simulated Total OC Concentration} with IMPROVE Observations (circles)
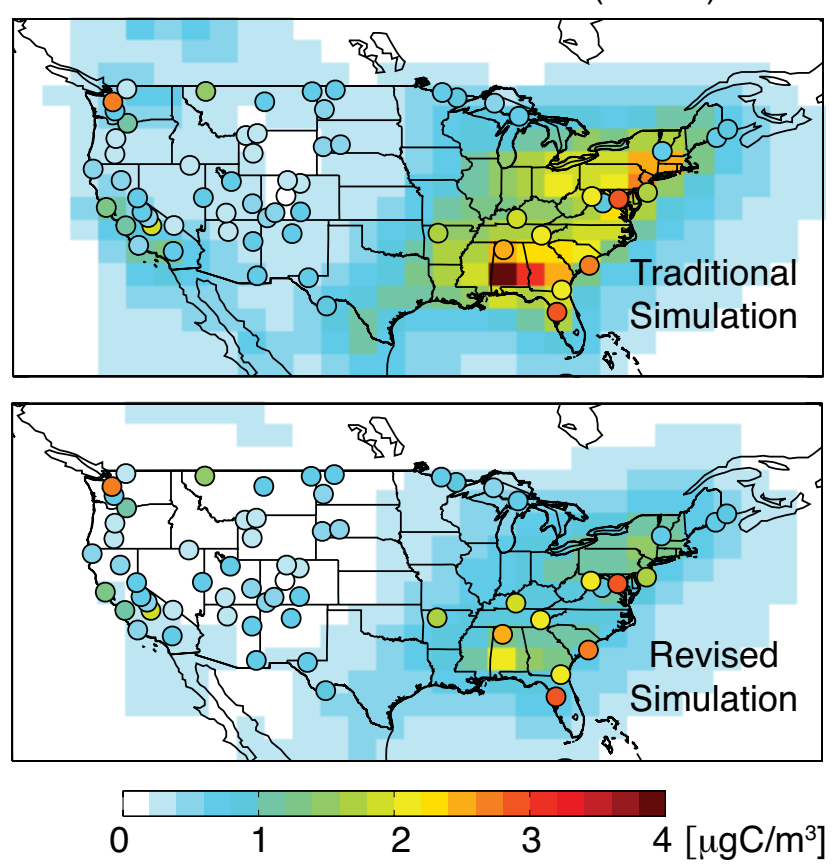

Fig. 7. Winter (December-January-February 2000) surface total OC concentration from $2^{\circ} \times 2.5^{\circ}$ (GEOS-4) simulations for the traditional and revised frameworks. Total OC includes POA and SOA from traditional precursors, IVOCs, and SVOCs. IMPROVE observations (averaged over DJF for year 2000) are overlaid in circles. An outlier value of $>27 \mu \mathrm{g} \mathrm{C} / \mathrm{m}^{3}$ has been removed from the IMPROVE observations. Only sites with valid data for at least half of the DJF 2000 season are shown. are highly uncertain, and in the $2 * I V O C$ simulation, the IVOC emissions are doubled. For the $2 * S V O C$ simulation, the traditional POA inventory is doubled to obtain SVOC emissions $\left(G_{R} / P O A_{R}=1\right)$. Two simulations are also performed to address uncertainties in the SVOC and O-SVOC partitioning coefficients. In SVOC $K^{*} 10$, the SVOC emissions are a factor of 10 less volatile than in the Revised simulation, having saturation concentrations $\left(1 / \mathrm{K}_{\mathrm{OM}}\right)$ of 2 and $160 \mu \mathrm{g} / \mathrm{m}^{3}$. The $100 \times$ decrease in saturation concentration is maintained so that the corresponding O-SVOCs have saturation concentrations of 0.02 and $1.6 \mu \mathrm{g} / \mathrm{m}^{3}$. For $O$-SVOC $K^{*} 10$, the SVOCs have the same saturation concentration as in the Revised simulation, but the SVOC oxidation products are a factor of 1000 times less volatile than their parent and thus have saturation concentrations of 0.02 and $1.6 \mu \mathrm{g} / \mathrm{m}^{3}$ (the same as in the SVOC $K^{*} 10$ simulation). An additional simulation, $H$-Law $/ 100$, reduces the effective Henry's Law coefficient relevant for scavenging of the secondary gas-phase semivolatile species to $10^{3} \mathrm{M} / \mathrm{atm} . \Delta H^{*} 2$, in which the enthalpy of vaporization is doubled to $83 \mathrm{~kJ} / \mathrm{mol}$ for all semivolatiles, is performed to examine wintertime surface concentrations as well. Parameters not listed in Table 6, such as biogenic hydrocarbon emissions, remain the same as in the base case.

\subsubsection{Winter US concentrations}

As mentioned previously, wintertime OA concentrations are dominated by contributions from POA and SOA from SVOCs and offer an opportunity to examine model performance while minimizing the effect of errors in the parameterization of biogenic SOA. Figures 8 and 9 show the response of wintertime surface concentrations to the sensitivity tests in Table 6 relative to the Traditional simulation. Table 7 shows the mean bias and normalized mean bias for the sensitvity simulations compared to the IMPROVE 
OC Concentration Relative to Traditional (Non-volatile POA) Simulation for DJF
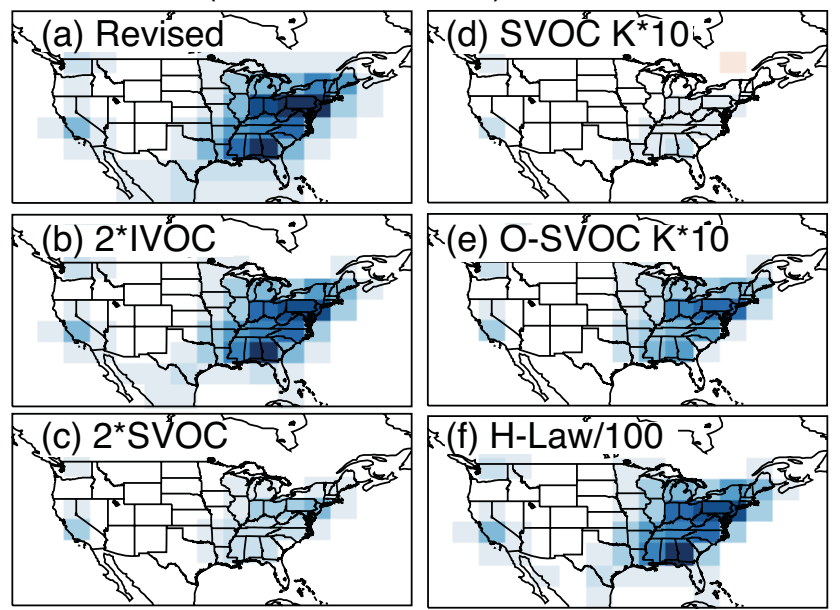

$-1.4$

$-0.7$

0.7

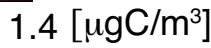

Fig. 8. DJF surface total OC concentration (POA, SOA from SVOCs, SOA from IVOCs, and traditional SOA) relative to nonvolatile POA simulation (POA and traditional SOA) using GISS meteorology at $4^{\circ} \times 5^{\circ}$. Sensitivity tests are given in Table 6 .

\section{OC Concentration Relative to} Traditional (Non-volatile POA) Simulation for DJF

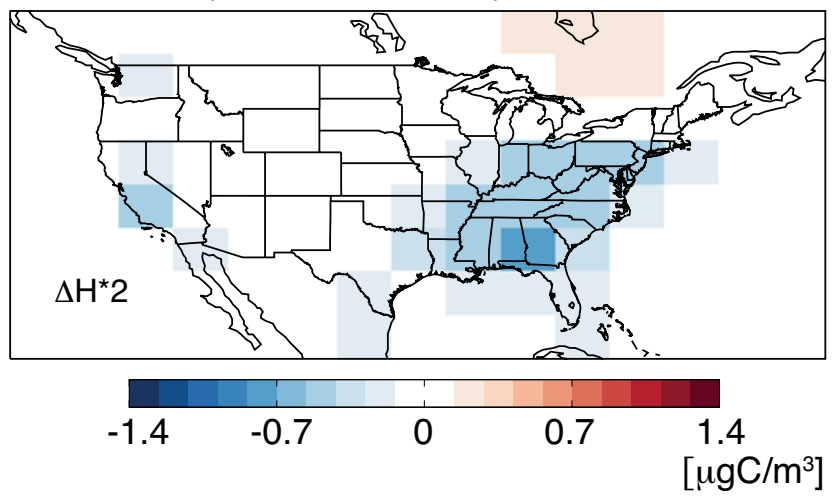

Fig. 9. DJF surface total OC concentration (POA, SOA from SVOCs, SOA from IVOCs, and traditional SOA) from a revised simulation in which the enthalpy of vaporization is $83 \mathrm{~kJ} / \mathrm{mol}$ relative to a non-volatile (traditional) POA simulation (POA and traditional SOA) using GISS meteorology at $4^{\circ} \times 5^{\circ}$.

network. Panel (a) of Fig. 8 represents the difference in surface concentrations between the Revised and Traditional simulations and highlights the fact that the Revised simulation results in a large decrease in surface concentrations as a result of POA evaporation. By doubling the IVOC emissions, $2 * I V O C$, surface concentrations increase slightly, but a significant underestimate still exists as IVOCs contribute generally a small fraction of the wintertime OA. Increasing the
SVOC emissions within the uncertainty of traditional POA inventories, $2 * S V O C$, brings surface concentrations much closer to the traditional simulation and thus observations, although a slight underestimate persists. The SVOC $K^{*} 10 \mathrm{sim}$ ulation is also effective in reducing the discrepancy between the new and traditional model formulations, since it is essentially making SVOCs more similar to traditional POA. In this simulation, roughly a factor of 6 to 10 more SVOCs with saturation concentrations of $1-2 \mu \mathrm{g} / \mathrm{m}^{3}$ are emitted than recommended by Grieshop et al. (2009b). A comparison to the $O$-SVOC $K^{*} 10$ simulation shows that the improvement in the SVOC $K^{*} 10$ simulation must be primarily a result of greater POA formation, not greater formation of SOA from SVOCs. The $O$-SVOC $K^{*} 10$ indicates that reducing the volatility of the SVOC oxidation products alone is not especially effective for bringing the model closer to observations. The $\mathrm{H}$ Law/100 simulation has only a small effect on winter surface concentrations, but can have a significant effect on the global budget of OA, which will be addressed in the next section. Figure 9 shows the change in OC surface concentration for DJF relative to the traditional simulation for the $\Delta H^{*} 2 \mathrm{sim}$ ulation. The new enthalpy produces a result similar to that of doubling the POA inventory ( $2 *$ SVOC simulation) in terms of reducing the discrepancy with the traditional simulation and observations. In conclusion, increasing the SVOC emissions, decreasing the SVOC emission volatility, or increasing the enthalpy of vaporization effectively reduce measurement/model discrepancy, although significant underestimates of the seasonal mean $\mathrm{OC}$ concentration persist (mean bias of $-0.51 \mu \mathrm{gC} / \mathrm{m}^{3}$ for $2 * S V O C,-0.44 \mu \mathrm{gC} / \mathrm{m}^{3}$ for SVOC $K^{*} 10$, and $-0.50 \mu \mathrm{gC} / \mathrm{m}^{3}$ for $\Delta H^{* 2}$ compared to the IMPROVE observations). The reduction in volatility in $S V O C K^{*} 10$ may be too extreme, and the higher enthalpy of vaporization may not be appropriate for lumped organics that span a relatively large range of volatility (Donahue et al., 2006). However, the increase in SVOC emissions, $2 * S V O C$, lies within the uncertainty of the POA emission inventory in the work of Bond et al. (2004). Tripling the POA emission inventory to obtain SVOC emissions (not shown) results in DJF OC concentrations about $1 \mu \mathrm{g} \mathrm{C} / \mathrm{m}^{3}$ higher than in the traditional simulation. The possibility remains that IVOCs could be underestimated by a substantially larger amount than examined here, or that the doubling of IVOC emissions in combination with doubling the POA emission inventory may provide a good present-day simulation. Additional constraints as well as a correct treatment of SOA temperature dependence are needed to assess the optimal model parameters.

For reference, Fig. S2 (see supplement, http://www.atmos-chem-phys.net/10/4377/2010/

acp-10-4377-2010-supplement.pdf) shows the effects of the first six sensitivity simulations on surface level June-July-August OC concentrations. The summertime simulations also indicate that increasing the SVOC emissions or decreasing the SVOC emission volatility are effective ways of reducing the discrepancy with the traditional simulation. 
Sensitivity of Global OA Source to Model Parameters Relative to Traditional Simulation

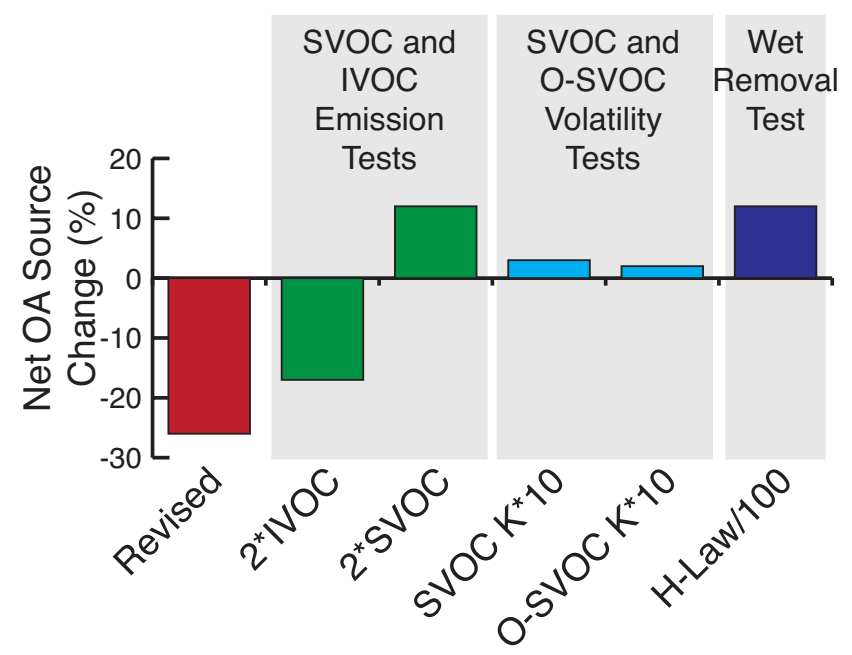

Fig. 10. Change in global OA net source (from all types of organic aerosol) for sensitvitiy tests. Values are relative to traditional simulation at $4^{\circ} \times 5^{\circ}$ using GISS meteorology. Sensitivity tests are given in Table 6 .

However, since the summer OA is dominated by contributions from biogenic SOA, future updates to this source of SOA will likely have significant effects on the summertime predictions.

\subsubsection{Global budget sensitivity}

Figure 10 shows the effect of the different sensitivity simulations on the global OA production rate compared to the Traditional simulation (all simulations use GISS meteorology at $4^{\circ} \times 5^{\circ}$ resolution). The Traditional simulation (at $4^{\circ} \times 5^{\circ}$ ) predicts $80 \mathrm{Tg} / \mathrm{yr}$ of net $\mathrm{OA}$ production using an $\mathrm{OM} / \mathrm{OC}$ ratio of 2.1 for POA. The net OA source for the Traditional simulation includes the emission rate of non-volatile POA. As mentioned previously, the Revised simulation leads to a decrease of the net global OA source $(-26 \%$, see Table 5 for $2^{\circ} \times 2.5^{\circ}$ simulation results), but an increase of the OA lifetime due to a shift of production away from the surface. Doubling the IVOC emissions $(2 * I V O C)$ increases the global OA production rate compared to the Revised simulation, but not compared to the Traditional simulation ( $-17 \%$ compared to Traditional). Doubling the POA emission inventory to obtain SVOC emissions $(2 * S V O C)$, however, leads to an OA source that exceeds the Traditional simulation by $12 \%$. The SVOC $K^{*} 10$ and $O$-SVOC $K^{*} 10$ simulations lead to a global production rate slightly larger than in the Traditional simulation ( $+3 \%$ and $+2 \%$ respectively). The decrease in effective Henry's Law coefficient significantly increases the OA source $(+12 \%)$ and lifetime due to less effective wet removal.
Table 7. Mean bias (MB) in $\mu \mathrm{gC} / \mathrm{m}^{3}$ and normalized mean bias (NMB) in percent (\%) for the sensitivity simulations for DJF 2000 $\left(M B=\frac{1}{N} \sum_{i=1}^{N}\left(P_{i}-O_{i}\right), N M B=100 \% * \sum_{i=1}^{N}\left(P_{i}-O_{i}\right) / \sum_{i=1}^{N}\left(O_{i}\right)\right.$, where $\mathrm{P}_{i}$ are the model predictions and $\mathrm{O}_{i}$ are the IMPROVE observations at $\mathrm{N}$ locations). IMPROVE observations are shown in Fig. 7. Sensitivity simulations are outlined in Table $6.2^{\circ} \times 2.5^{\circ}$ simulations use GEOS 4 meteorology. $4^{\circ} \times 5^{\circ}$ simulations use GISS GCM meteorology.

\begin{tabular}{lcc}
\hline Simulation & $\begin{array}{c}\mathrm{MB} \\
{\left[\mu \mathrm{gC} / \mathrm{m}^{3}\right]}\end{array}$ & $\begin{array}{c}\mathrm{NMB} \\
{[\%]}\end{array}$ \\
\hline $2^{\circ} \times 2.5^{\circ}$ Traditional & -0.20 & -22 \\
$2^{\circ} \times 2.5^{\circ}$ Revised & -0.59 & -63 \\
$4^{\circ} \times 5^{\circ}$ Traditional & -0.37 & -39 \\
$4^{\circ} \times 5^{\circ}$ Revised & -0.70 & -75 \\
$4^{\circ} \times 5^{\circ} 2^{*}$ IVOC & -0.68 & -73 \\
$4^{\circ} \times 5^{\circ} 2^{*}$ SVOC & -0.51 & -55 \\
$4^{\circ} \times 5^{\circ}$ SVOC K*10 & -0.44 & -47 \\
$4^{\circ} \times 5^{\circ}$ O-SVOC K*10 & -0.60 & -64 \\
$4^{\circ} \times 5^{\circ} \mathrm{H}$-Law $/ 100$ & -0.67 & -71 \\
$4^{\circ} \times 5^{\circ} \Delta \mathrm{H}^{*} 2$ & -0.50 & -54 \\
\hline
\end{tabular}

Fraction of Modern Carbon in SVOC Emissions
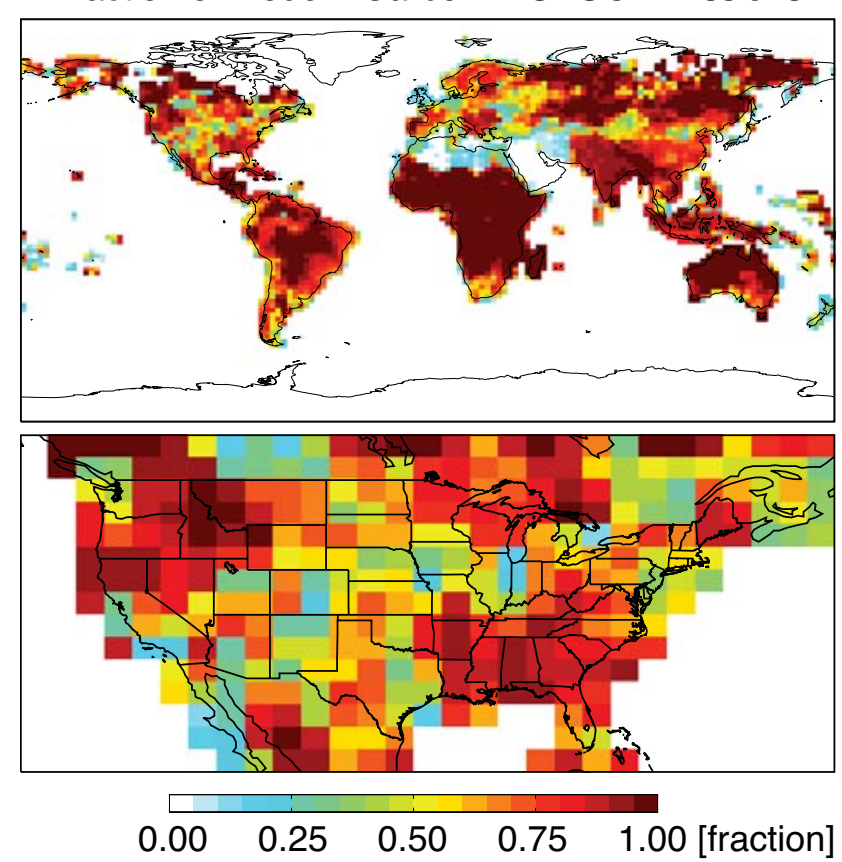

Fig. 11. Fraction of SVOC emissions from modern carbon: (Biomass+Biofuel)/(Biomass+Biofuel+Anthropogenic). 
Fraction of Modern Carbon in IVOC Emissions
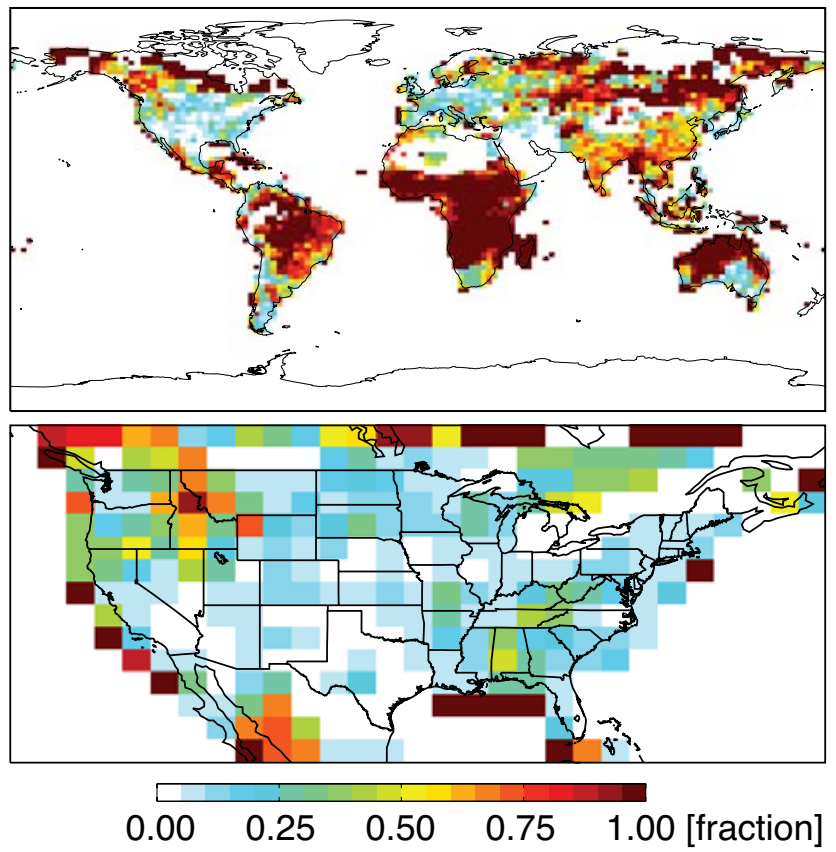

Fig. 12. Fraction of IVOC emissions from modern carbon: (Biomass+Biofuel) $/($ Biomass+Biofuel+Anthropogenic). Note that the high contribution of modern carbon just of the coast of the US (such as over the Gulf of Mexico) results from small, but nonzero emissions from biofuel burning. Biofuel emissions occur in these location as a result of degredation of the emission inventory as it is regrided from $0.25^{\circ} \times 0.25^{\circ}$ to $1^{\circ} \times 1^{\circ}$ and then $2^{\circ} \times 2.5^{\circ}$ or $4^{\circ} \times 5^{\circ}$ horizontal resolution for use in GEOS-Chem.

Production of organic aerosol in the Revised framework at $2^{\circ} \times 2.5^{\circ}$ horizontal resolution with GEOS-4 is estimated to be $67 \mathrm{Tg} / \mathrm{yr}$ compared to $87 \mathrm{Tg} / \mathrm{yr}$ in the Traditional framework. The lowest global net production rate out of all simulations (at all resolutions and meteorologies) performed occurs with the Revised framework at $4^{\circ} \times 5^{\circ}$ horizontal resolution (GISS) and is about $60 \mathrm{Tg} / \mathrm{yr}$. The sensitivity tests at $4^{\circ} \times 5^{\circ}$ horizontal resolution indicate that the global production rate could be $12 \%$ higher than that predicted in the traditional simulation if SVOC emissions are significantly underestimated or wet deposition of the gas-phase semivolatiles is less effective. The $2 * S V O C$ test was repeated using the $2^{\circ} \times 2.5^{\circ}$ resolution (with GEOS-4 meteorology, see supplement) and the increase in production over the Traditional simulation was confirmed to be roughly the same as in the coarser resolution simulations (13\%). Thus, the range of estimates for global OA production examined here is approximately 60 to $100 \mathrm{Tg} / \mathrm{yr}$.

One additional sensitivity test was performed to examine the effect of the biogenic emission inventory on the OA budget. Using the GEIA biogenic inventory (Guenther et al., 1995) instead of MEGAN (Guenther et al., 2006) results in a modest (about 7\%) increase in the global OA production rate. For the $4^{\circ} \times 5^{\circ}$ resolution with GISS GCM III meteorology, GEIA estimates global isoprene sources to be $490 \mathrm{Tg} / \mathrm{yr}$ which is $24 \%$ higher than the MEGAN estimate. Terpene emissions increase by $14 \%$ compared to the MEGAN inventory. Isoprene SOA increases to $8 \mathrm{Tg} / \mathrm{yr}$, and terpene SOA increases to $5 \mathrm{Tg} / \mathrm{yr}$. However, the global OA budget (burden, sources, and losses) remains within $10 \%$ of the estimate using the MEGAN inventory. Current global chemical transport models and chemical mechanisms are known to have significant issues simulating isoprene and $\mathrm{OH}$ levels under low- $\mathrm{NO}_{\mathrm{x}}$ conditions like over the Amazon (Lelieveld et al., 2008; Butler et al., 2008; Archibald et al., 2010). Improved isoprene chemistry and/or improved isoprene SOA formation parameterizations could lead to substantial changes in the global estimate of SOA from isoprene.

\subsection{Modern vs. fossil carbon}

The fraction of modern vs. fossil aerosol carbon can provide an additional model constraint. The major contributors to US surface OA are predicted to be biogenic hydrocarbons (mainly in summer) and SVOCs followed by IVOCs and aromatics. Slightly more than half of the global aromatic emissions are from fossil fuel sources (Henze et al., 2008). The fraction of modern carbon in POA and SOA formed from SVOCs is not separately tracked but depends on the composition of the SVOC emissions. Figure 11 shows the fraction of modern carbon in the SVOC emissions globally and for the US. Biomass and biofuel burning produce modern $\mathrm{C}$ while anthropogenic sources are assumed to be $100 \%$ fossil. Figure 11 indicates that aerosol from SVOCs over the US has a significant and often dominant modern component. The IVOC emissions over the US are dominated by fossil carbon (Fig. 12).

The radioisotope, ${ }^{14} \mathrm{C}$, can be used to distinguish between modern (contemporary) and fossil carbon in ambient samples. ${ }^{14} \mathrm{C}$ is produced in the upper atmosphere by cosmic rays and has a half life of about 5700 years. Fossil carbon should be depleted in ${ }^{14} \mathrm{C}$, while modern carbon from sources such as biogenic VOC oxidation or wood burning should be enriched. Carbon isotope measurements have been performed in various locations to determine the contribution of modern and fossil carbon to total aerosol carbon. Carbon isotope measurements in the Southern California air basin in 1987 indicate that $30-40 \%$ of the fine particulate carbon was modern (Kaplan and Gordon, 1994). Szidat (2009) found OC was usually more than 50\% modern for cities in Switzerland and Sweden, with biogenic OA likely responsible for modern carbon in summer and wood burning responsible in winter. Carbon isotope analysis of individual PAHs in Sweden indicates that residential wood burning is the dominant source of PAHs in the winter (Sheesley et al., 2009). During two field campaigns (2003 and 2006), Mexico City was found to have, on average, 70\% modern carbon (Marley et al., 2009). 
In the analysis of aerosol at 12 US sites by Schichtel et al. (2008), total carbon was found to be about $50 \%$ modern in urban, 70-97\% modern in near-urban, and 82 to $100 \%$ modern in remote areas. In short, the carbonaceous aerosol in a variety of locations exhibits significant amounts of modern carbon, with the fraction of modern carbon increasing with distance from urban centers (Schichtel et al., 2008). These observations lend support to the hypothesis that SVOCs contribute significantly to ambient OA and that scaling up SVOC emissions may be more justified than scaling up IVOC emissions. However, when scaling up the POA emission inventory to obtain SVOC emissions in this work, all sources were scaled up equally. Scaling up the POA emission inventories from all sources equally is supported by the work of Shrivastava et al. (2006) and others that indicate that diesel and wood combustion exhaust have very similar volatility profiles in the SVOC range. Thus, traditional POA inventories may represent the same fraction of SVOC emissions in each case. But, work by Shrivastava et al. (2008) and Grieshop et al. (2009a) indicate that diesel combustion or other anthropogenic sources may produce relatively more IVOCs than wood burning. The volatility at which the wood burning and anthropogenic emission volatility profiles diverge is not known (this works assumes it is about $10^{4} \mu \mathrm{g} / \mathrm{m}^{3}$ based on sources that have been examined), and the fraction of SVOCs captured by diesel exhaust and wood burning POA inventories might differ leading to the need for source specific SVOC scaling factors. SVOCs from anthropogenic sources could be underestimated to a greater extent by the traditional POA inventory than SVOCs from biomass or biofuel burning sources which means the fossil carbon SVOC emissions may be underestimated.

Using alkanes to obtain the spatial distribution of IVOC emissions would likely lead to large estimates of anthropogenic sources and small estimates of wood burning sources since wood burning is not a large source of intermediate volatility alkanes (approximately C17) (Schauer et al., 2001). Thus, the IVOC composition would be shifted even more toward fossil fuel sources than predicted by the naphthalene spatial distribution. Since ambient data indicate a large modern $\mathrm{C}$ component to aerosol, the alkane distribution would further diminish the expected role of IVOCs in ambient organic aerosol formation.

Modern carbon, however, should be distinguished from non-anthropogenic carbon. Biofuel combustion from activities like residential wood burning is a significant anthropogenic source of modern carbon. The high fraction of modern carbon in urban areas, especially compared to rural areas, in the winter suggests substantial contributions of wood burning to aerosol carbon in the US (Bench et al., 2007; Schichtel et al., 2008).

\section{Model uncertainties}

Modeling organic aerosol production from SVOCs and IVOCs requires extrapolating experimental results obtained under idealized conditions or a from limited set of ambient observations to global conditions. As a result, potential discrepancies between experiments, observations, and the atmosphere must be addressed.

\subsection{IVOC behavior}

Naphthalene is used as a surrogate to represent SOA formation from the entire set of IVOC emissions (see Sect. 2.5). Other important classes of IVOCs include alkanes and phenol type compounds. A significant portion of the IVOCs may also be part of the gas-phase UCM. Naphthalene is expected to be more representative of phenol-type compounds than alkanes would be, but does naphthalene exhibit behavior representative of IVOCs? High- $\mathrm{NO}_{\mathrm{x}}$ oxidation of an alkane IVOC surrogate in the work of Presto et al. (2009) resulted in less volatile SOA than low- $\mathrm{NO}_{\mathrm{x}}$ oxidation, opposite of the behavior observed for naphthalene (Chan et al., 2009). However, in terms of yields, the IVOC, heptadecane, is predicted to react slightly faster with $\mathrm{OH}$ than naphthalene and result in a slightly lower but similar (20\% vs. $26 \%)$ yield of SOA under high- $\mathrm{NO}_{\mathrm{x}}$ conditions (Chan et al., 2009).

Assuming naphthalene is a good surrogate for IVOCs, is naphthalene behavior accurately captured by the current parameterization? Chamber experiments are likely to be most representative of the atmosphere when aerosol loadings are low and oxidation times are long. Low- $\mathrm{NO}_{\mathrm{x}}$ conditions in which the peroxy radical from IVOC oxidation is expected to react with $\mathrm{HO}_{2}$ is predicted to form a non-volatile aerosol product based on chamber experiments (Chan et al., 2009). However, chamber aerosol studies typically do not access very low organic concentrations, and thus what appears nonvolatile in a chamber study may actually be semivolatile under atmospheric conditions. As a result, the dominance of aromatic and IVOC aerosol in remote regions near the surface could be a model artifact. In addition, aerosol from the $\mathrm{RO}_{2}+\mathrm{RO}_{2}$ pathway, which should be minor, is not accounted for in our model.

Another option for treating SOA from IVOCs is the volatility basis set approach with parameters by Robinson et al. (2007) or Grieshop et al. (2009a). IVOC compounds can be lumped into a series of volatility bins and oxidized with a prescribed reduction in volatility and increase in mass. With multiple generations of oxidation and no fragmentation reactions, this approach can give a very high yield of aerosol from IVOCs which could be on the order of $200 \%$ or more (J. Jimenez, personal communication, 2010). The yield is especially high using the parameters introduced by Grieshop et al. (2009a). Modeling for the Mexico City area indicates that the Grieshop et al. (2009a) parameters with multigenerational oxidation tend to overestimate organic aerosol 
downwind of the city (Hodzic et al., 2010). While the Robinson et al. (2007) parameters may give more realistic predictions of the total OA, the aerosol they produce predicts too low of an O:C ratio (Hodzic et al., 2010). Currently, Robinson et al. (2007) or Grieshop et al. (2009a) frameworks likely cannot be consistent with ambient measurements indicating that OOA is relatively non-volatile (Cappa and Jimenez, 2010) without predicting too much of an increase in mass or too low of an increase in $\mathrm{O}: \mathrm{C}$.

Simulations presented in this work obtain a lower net yield of aerosol from IVOCs of about $30 \%$ indicating a more minor role of IVOC aerosol. Both the basis set and the naphthalenelike approach used here may be similar in that near-source (i.e. high- $\mathrm{NO}_{\mathrm{x}}$ ) SOA tends to be semivolatile, while remote (i.e. low- $\mathrm{NO}_{\mathrm{x}}$ ) SOA tends to be relatively non-volatile. However, the reason for this trend and overall yields are very different in each case. Naphthalene can continue to serve as an IVOC surrogate until more information on IVOC emissions and/or IVOC oxidation behavior is obtained.

\subsection{SVOC volatility}

The parameterization for SVOC volatility uses two surrogate compounds to represent SVOC emissions, in contrast to the volatility basis set which uses 4 or more volatility classes to represent emissions. Very low-volatility compounds (those with $C^{*}<0.1 \mu \mathrm{g} / \mathrm{m}^{3}$ ) will be found in the aerosol phase under almost all atmospherically relevant conditions. The lowest volatility SVOC emitted in this work is assumed to have a $C^{*}$ of $20 \mu \mathrm{g} / \mathrm{m}^{3}$ (at $300 \mathrm{~K}$ ), and we likely do not represent SVOCs with saturation concentrations below $1 \mu \mathrm{g} / \mathrm{m}^{3}$. The volatility basis set approaches of Robinson et al. (2007) and Grieshop et al. (2009b) distribute lowvolatility organic compounds with $C^{*} \mathrm{~s}$ down to $0.01 \mu \mathrm{g} / \mathrm{m}^{3}$. Grieshop et al. (2009b) indicate that up to 5\% of SVOC emissions may be considered non-volatile under atmospheric conditions since the $C^{*}$ values are below $1 \mu \mathrm{g} / \mathrm{m}^{3}$. However, emissions of these very low-volatility compounds are not well constrained. Fits of wood-smoke data tend to diverge at organic concentrations less than about $100 \mu \mathrm{g} / \mathrm{m}^{3}$ (Shrivastava et al., 2006). Thermodenuder data can provide additional constraints but also show significant variability with somewhere between 80 and $40 \%$ of the wood-smoke aerosol evaporating at $50^{\circ} \mathrm{C}$ (Grieshop et al., 2009b). Grieshop et al. (2009a) included low-volatility compounds in their model of chamber aging and found that including a $9 \%$ contribution of $C^{*} 0.1$ and 0.01 degraded model performance. The two volatility components used here should roughly capture the partitioning of species with $C^{*}$ of 1 to $10^{4} \mu \mathrm{g} / \mathrm{m}^{3}$ and thus capture $95 \%$ (for wood burning) to $98 \%$ (for diesel) of the SVOC mass. If a $5 \%$ low-volatility emission were to be included in our simulation, it could account for up to $2 \mathrm{Tg} C / \mathrm{yr}$ of net primary organic aerosol formation. This could easily more than quadruple the net POA source, but would have a small effect on the global aerosol production rate, which is predicted to exceed $60 \mathrm{Tg} / \mathrm{yr}$.

\subsection{Horizontal resolution and inter-annual variability}

Sensitivity tests performed indicate that doubling SVOC emissions leads to more realistic surface-level OC concentrations for the US in winter. This conclusion was reached using sensitivity tests for DJF in year 2000 with GISS meteorology at $4^{\circ} \times 5^{\circ}$ horizontal grid resolution. The same tests were repeated for DJF in year 2001 with GISS meteorology at $4^{\circ} \times 5^{\circ}$ to confirm that this conclusion is not highly sensitive to the choice of meteorological year (see Supplement Fig. S3, http://www.atmos-chem-phys.net/10/4377/ 2010/acp-10-4377-2010-supplement.pdf). Three of the tests in Table 6 were also performed for year 2000 DJF using GEOS-4 meteorology at $2^{\circ} \times 2.5^{\circ}$ horizontal grid resolution. Thus, the robustness of the conclusions with respect to meteorological year as well as horizontal grid resolution and meteorology can be determined. GISS tests for year 2000 and 2001 both indicate that doubling SVOC emissions brings concentrations closer to those observed, but still leaves a slight underestimate that may be larger in 2001. Using the GEOS-4 meteorology at $2^{\circ} \times 2.5^{\circ}$ indicates that concentrations might actually be higher compared to the traditional simulation in the northeast when SVOC emissions are doubled (Fig. S4, http://www.atmos-chem-phys.net/10/ 4377/2010/acp-10-4377-2010-supplement.pdf). In conclusion, years 2000 and 2001 are roughly similar in terms of the effects of the sensitivity simulations on DJF surface OC. The GEOS-4 $2^{\circ} \times 2.5^{\circ}$ simulation confirms that doubling SVOC emissions is reasonable. However, these tests and the fact that the $2^{\circ} \times 2.5^{\circ}$ and $4^{\circ} \times 5^{\circ}$ simulations have different mean biases (Table 7) illustrate that tuning a model based on one simulation may not produce the same result for other simulations (like the Northeast at $2^{\circ} \times 2.5^{\circ}$ vs. $4^{\circ} \times 5^{\circ}$ ). Any tuning of the model emissions should be based on multiple constraints and/or a large observational data set.

\section{Conclusions}

In this study, we present a global estimate, using GEOSChem, of organic aerosols from primary emissions of gases and aerosols with saturation concentrations of roughly less than $10^{6} \mu \mathrm{g} / \mathrm{m}^{3}$. Sources of these compounds include biomass burning, biofuel burning, and anthropogenic activities. POA, which has traditionally been considered nonvolatile, is replaced by a pool of semivolatile organic compounds, denoted here as SVOCs, that can partition between the gas and aerosol phases and can be oxidized in the gas phase to less volatile species that partition even more effectively to the aerosol phase. In addition, intermediate volatility organic compounds, denoted as IVOCs, which exist entirely in the vapor phase, can undergo oxidation in the 
gas phase to form lower volatility species that partition to the aerosol phase (based on naphthalene-like behavior). Aerosol that results from the oxidation of any of these gas-phase species is termed secondary organic aerosol (SOA). Globally, biomass burning and anthropogenic sources contribute similar amounts of IVOCs. Over the US, the dominant fraction of IVOCs arises from anthropogenic sources.

Implementation of semivolatile POA generally leads to decreases in predicted surface-level concentrations of organic aerosol due to a portion of the POA evaporating upon emission. US winter organic carbon concentrations from the IMPROVE network are used to assess the accuracy of model predictions under conditions in which the effect of uncertainties in biogenic SOA formation are likely to be at a minimum. Sensitivity tests indicate that uncertainties in the IVOC emissions, the Henry's Law coefficient for scavenging of gas-phase semivolatiles, or the assumed 100x (or 1000x) decrease in volatility upon oxidation of the primary SVOCs are not especially influential in reducing the discrepancy between predictions and observations. However, a significant increase in SVOC emissions, a reduction of the volatility of the SVOC emissions, or an increase in the enthalpy of vaporization to $83 \mathrm{~kJ} / \mathrm{mol}$ all lead to an appreciable reduction of the prediction/measurement discrepancy. The reduction in SVOC volatility examined is likely too extreme, but scaling up the SVOC emissions by a factor of 2 seems reasonable considering that traditional inventories do not necessarily capture SVOCs emitted in the gas phase. The higher enthalpy of vaporization is also supported by a recent study (Epstein et al., 2010) but may not be appropriate for lumped organics (Donahue et al., 2006).

The range of estimates for global organic aerosol production is $60-100 \mathrm{Tg} / \mathrm{yr}$. Virtually all of this production is SOA, since POA tends to evaporate and oxidize in the gas phase after emission. The sensitivity tests examine uncertainties one parameter at a time, so the range in organic aerosol production could be larger if uncertainties in multiple parameters were to be accounted for simultaneously. If current traditional POA inventories capture only about one-half of the SVOC emissions and gas-phase semivolatiles are much less aggressively wet removed, this would lead to an estimate of global OA production that is not inconsistent with top-down calculations, such as those by (Goldstein and Galbally, 2007) who estimated SOA production ranging from $140 \mathrm{Tg} / \mathrm{yr}$ and up. Much of the increase in SOA shown here compared to previous estimates, like those by Henze et al. (2008), results from reclassification of most of the POA as SOA due to evaporation and subsequent oxidation. Also note that the present estimate of OA production is net production, so a species that partitions to the aerosol, but later evaporates, is not counted in net aerosol. The effects of chemical aging of SOA beyond that reflected in current chamber experiments is not explicitly considered.

SVOC and IVOC emissions are predicted to have different fractions of modern and fossil carbon which can provide constraints on estimates of SVOC and IVOC aerosol. In the US, SVOC emissions have a significant biofuel component which, along with biomass burning emissions, results in a significant fraction of modern C. US IVOC emissions, however, are predicted to be predominantly fossil. The high fraction of modern carbon observed in organic aerosol in the US is consistent with an important contribution of aerosol from SVOCs.

While representing POA as semivolatile is clear progress in modeling of organic aerosol, additional constraints are needed to sharpen estimates. Information in the form of improved SVOC and IVOC emission estimates or data (such as ${ }^{14} \mathrm{C}$ fractions, O:C ratios, AMS PMF components (OOA, HOA), correlation with gas-phase tracers (Weber et al., 2007; de Gouw et al., 2005), or identification of marker compounds (Bhave et al., 2007)) that allow for the determination of sources of OA can help to constrain models.

\section{Appendix A}

\section{Effect of meteorology and grid resolution on global OA budget}

The effect of changes in meteorology and horizontal grid resolution on the global OA budget are briefly examined. GEOS-Chem with GEOS-4 and GISS GCM III meteorology at $4^{\circ} \times 5^{\circ}$ has been compared previously with a focus on tropospheric ozone budgets (Wu et al., 2007). Wu et al. (2007) found that an important difference between the GEOS assimilated and GISS GCM meteorology is the treatment of wet convection. The GISS model allows for non-precipitating condensed water, and in GEOS-Chem with GISS meteorology, soluble species are not scavenged in shallow convective updrafts below $700 \mathrm{hPa}$. Differences in clouds can lead to differences in oxidant levels. Boundary layer turbulence is also treated slightly differently in GEOS-Chem with GEOS meteorology versus GEOS-Chem with GISS meteorology (Wu et al., 2007). Although these differences exist between the two meteorologies, organic aerosols have been successfully simulated and compared to observations using GEOS meteorology at $2^{\circ} \times 2.5^{\circ}$ resolution (Park et al., 2003) and $1^{\circ} \times 1^{\circ}$ nested grid resolution (Park et al., 2006) and using GISS meteorology at $4^{\circ} \times 5^{\circ}$ resolution (Liao et al., 2007). Note that the $2^{\circ} \times 2.5^{\circ}$ GEOS and $4^{\circ} \times 5^{\circ}$ GISS simulations should be viewed as 2 different realizations of year 2000 conditions and should not be the same, but show similar responses to changes in parameters.

Table A1 shows the effect of changes in meteorology and resolution on precursor emissions, OA net production, aerosol lifetime, and global $\mathrm{OH}$. Natural emissions such as lightning $\mathrm{NO}_{\mathrm{x}}$ and biogenic hydrocarbons that are parameterized based on meteorology are predicted to change significantly in some cases. The change to $4^{\circ} \times 5^{\circ}$ GISS meteorology results in $7 \%$ higher terpene emissions, but $11 \%$ 
Table A1. Effect of model resolution and meteorology on global OA budget. $2^{\circ} \times 2.5^{\circ}$ simulations are performed with GEOS- 4 assimilated meteorology. $4^{\circ} \times 5^{\circ}$ simulations were performed with GISS GCM Model 3 meteorology. Both simulations use revised framework (semivolatile POA, SOA from SVOCs, and SOA from IVOCs). To convert POA to Tg C, divide by 1.4. To convert SOA to $\mathrm{Tg} \mathrm{C}$, divide by 2.1 .

\begin{tabular}{|c|c|c|c|}
\hline Process & $\begin{array}{c}2^{\circ} \times 2.5^{\circ} \\
\text { Assimilated } \\
\text { Meteorology }\end{array}$ & $\begin{array}{c}4^{\circ} \times 5^{\circ} \\
\text { GCM } \\
\text { Meteorology }\end{array}$ & $\begin{array}{c}\text { Difference } \\
(\%)\end{array}$ \\
\hline \multicolumn{4}{|l|}{$\begin{array}{l}\text { Precursor Emisions } \\
{[\mathrm{Tg} / \mathrm{yr}]}\end{array}$} \\
\hline SVOCs & 52 & 52 & $0 \%$ \\
\hline IVOCs & 16 & 16 & $0 \%$ \\
\hline terpenes & 115 & 123 & $7 \%$ \\
\hline alcohols & 38 & 38 & $1 \%$ \\
\hline sesquiterpenes & 15 & 15 & $0 \%$ \\
\hline isoprene & 446 & 396 & $-11 \%$ \\
\hline aromatics & 18 & 18 & $0 \%$ \\
\hline \multicolumn{4}{|c|}{ OA Net Production by Parent Hydrocarbon Class [Tg/yr] } \\
\hline SVOC (POA) & 0.7 & 1.1 & $56 \%$ \\
\hline SVOC (SOA) & 38.3 & 37.0 & $-3 \%$ \\
\hline IVOCs & 5.2 & 5.1 & $-2 \%$ \\
\hline terpenes & 5.6 & 4.1 & $-26 \%$ \\
\hline alcohols & 1.1 & 0.8 & $-32 \%$ \\
\hline sesquiterpenes & 1.5 & 1.0 & $-35 \%$ \\
\hline isoprene & 11.2 & 6.7 & $-40 \%$ \\
\hline aromatics & 3.5 & 3.3 & $-6 \%$ \\
\hline Total OA Production & 67 & 59 & $-12 \%$ \\
\hline \multicolumn{4}{|c|}{ Tropospheric Lifetime Against Deposition [days] } \\
\hline POA & 17.4 & 9.5 & $-45 \%$ \\
\hline SVOC SOA & 7.7 & 5.3 & $-31 \%$ \\
\hline IVOC SOA & 6.5 & 4.4 & $-31 \%$ \\
\hline Traditional SOA & 11.4 & 9.1 & $-20 \%$ \\
\hline \multicolumn{4}{|c|}{ Mass weighted $\mathrm{OH}$ Concentration $\left[\mathrm{molec} \mathrm{cm}^{-3}\right.$ ] } \\
\hline$[\mathrm{OH}]$ & $1.07 \times 10^{6}$ & $1.03 \times 10^{6}$ & $-4 \%$ \\
\hline
\end{tabular}

Table A2. Traditional (non-volatile POA) simulation for $2^{\circ} \times 2.5^{\circ}$ and $4^{\circ} \times 5^{\circ}$ grid resolution. $2^{\circ} \times 2.5^{\circ}$ simulations are performed with GEOS- 4 assimilated meteorology. $4^{\circ} \times 5^{\circ}$ simulations were performed with GISS GCM Model 3 meteorology.

\begin{tabular}{llllll}
\hline \multicolumn{7}{c}{$\begin{array}{l}\text { Tropospheric } \\
\text { burden } \\
{[\mathrm{Tg} C]}\end{array}$} & $\begin{array}{l}\text { Emission } \\
{[\mathrm{Tg} \mathrm{C} / \mathrm{yr}]}\end{array}$ & $\begin{array}{l}\text { Wet } \\
\text { Deposition } \\
{[\mathrm{Tg} \mathrm{C} / \mathrm{yr}]}\end{array}$ & $\begin{array}{l}\text { Dry } \\
\text { Deposition } \\
{[\mathrm{Tg} \text { C/yr }]}\end{array}$ & $\begin{array}{l}\text { Tropospheric } \\
\text { Lifetime } \\
{[\text { days }]}\end{array}$ \\
\hline $2^{\circ} \times 2.5^{\circ}$ Traditional Non-volatile POA Simulation \\
Hydrophobic POA & 0.042 & 15 & 0.3 & 0.7 & 15 \\
Hydrophilic POA & 0.40 & 15 & 25 & 3.3 & 5.2 \\
Total POA & 0.44 & 29 & 25 & 4 & 5.5 \\
$4^{\circ} \times 5^{\circ}$ Traditional Non-volatile POA Simulation & & & \\
Hydrophobic POA & 0.039 & 15 & 0.7 & 1.2 & 7.3 \\
Hydrophilic POA & 0.26 & 15 & 23 & 3.9 & 3.5 \\
Total POA & 0.30 & 29 & 24 & 5 & 3.7 \\
\hline
\end{tabular}

lower isoprene emissions, presumably due to differences in temperature. Except for POA, the net OA production is expected to decrease. The change in global net OA production as a result of the change in resolution is relatively larger for biogenic SOA compared to the change in emissions. For example, although isoprene emissions are $11 \%$ lower at the coarser resolution, the production rate of isoprene SOA is $40 \%$ lower. Presumably, global OA production decreases as a result of lower isoprene emissions. SOA production could also decrease as a result of more effective deposition of the gas-phase precursors or semivolatiles. $\mathrm{OH}$ levels over the Amazon are generally slightly lower in the GCAP $4^{\circ} \times 5^{\circ}$ simulation compared to the $2^{\circ} \times 2.5^{\circ}$ simulation which supports lower isoprene SOA formation as well.

To gain further insight into the effects of changes in meteorology and resolution and why POA production may have increased at $4^{\circ} \times 5^{\circ}$, the effect of the changes on a traditional non-volatile POA simulation are shown in Table A2. Hydrophobic and hydrophilic forms of POA are separated. Hydrophobic POA is similar to the semivolatile POA, in that it is emitted but can be converted to another species (hydrophilic POA for the traditional simulation or SOA in the revised simulation). In the traditional simulation, for $4^{\circ} \times 5^{\circ}$ resolution compared to $2^{\circ} \times 2.5^{\circ}$, hydrophobic POA is more effectively wet and dry deposited as reflected by the higher deposition rates and shorter tropospheric lifetime against deposition. For production of semivolatile POA to increase at $4^{\circ} \times 5^{\circ}$ for the same SVOC emissions, POA must be more quickly lost to wet and dry deposition before it evaporates and reacts with $\mathrm{OH}$. The aerosol deposition velocity over land is generally higher for the $4^{\circ} \times 5^{\circ}$ GISS study than $2^{\circ} \times 2.5^{\circ}$ GEOS-4 study due to a higher friction velocity over land in the GISS meteorological fields. Thus, OA production can generally decrease as a result of lower isoprene SOA, but POA production can increase due to more aggressive deposition. SOA from SVOCs, IVOCs, and aromatics is only slightly affected by the change in resolution and meteorology.

Acknowledgements. The numerical simulations for this research were performed on Caltech's Division of Geological and Planetary Sciences Dell cluster. H. O. T. P. acknowledges support by a National Science Foundation Graduate Research Fellowship. This research has been supported by the US Environmental Protection Agency Science to Achieve Results (STAR) agreements RD-833749 and RD-83337001 and by the Office of Science (BER), US Department of Energy Grant No. DE-FG02-05ER63983. Although the research described in the article has been funded in part by the US Environmental Protection Agency's STAR program, it has not been subjected to any EPA review and therefore does not necessarily reflect the views of the Agency, and no official endorsement should be inferred. The authors would like to thank Arthur Chan, Jose Jimenez, Fabien Paulot, and Paul Wennberg for useful discussions.

Edited by: M. Kanakidou 


\section{References}

Aiken, A. C., Decarlo, P. F., Kroll, J. H., Worsnop, D. R., Huffman, J. A., Docherty, K. S., Ulbrich, I. M., Mohr, C., Kimmel, J. R., Sueper, D., Sun, Y., Zhang, Q., Trimborn, A., Northway, M., Ziemann, P. J., Canagaratna, M. R., Onasch, T. B., Alfarra, M. R., Prevot, A. S. H., Dommen, J., Duplissy, J., Metzger, A., Baltensperger, U., and Jimenez, J. L.: O/C and OM/OC ratios of primary, secondary, and ambient organic aerosols with high-resolution time-of-flight aerosol mass spectrometry, Environ. Sci. Technol., 42, 4478-4485, doi:10.1021/ES703009q, 2008.

Andreae, M. O. and Merlet, P.: Emission of trace gases and aerosols from biomass burning, Global Biogeochem. Cy., 15, 955-966, doi:10.1029/2000GB001382, 2001.

Archibald, A. T., Jenkin, M. E., and Shallcross, D. E.: An isoprene mechanism intercomparison, Atmos. Environ., doi:10.1016/J.ATMOSENV.2009.09.016, in press, 2010.

Atkinson, R.: Gas-phase tropospheric chemistry of volatile organic compounds: 1. Alkanes and alkenes, J. Phys. Chem. Ref. Data, 26, 215-290, 1997.

Atkinson, R. and Arey, J.: Atmospheric degration of volatile organic compounds, Chem. Rev., 103, 4605-4638, doi:10.1021/CR0206420, 2003.

Bench, G., Fallon, S., Schichtel, B., Malm, W., and McDade, C.: Relative contributions of fossil and contemporary carbon sources to $\mathrm{PM}_{2.5}$ aerosols at nine Interagency Monitoring for Protection of Visual Environments (IMPROVE) network sites, J. Geophys. Res., 112, D10205, doi:10.1029/2006JD007708, 2007.

Bey, I., Jacob, D. J., Yantosca, R. M., Logan, J. A., Field, B. D., Fiore, A. M., Li, Q. B., Liu, H. G. Y., Mickley, L. J., and Schultz, M. G.: Global modeling of tropospheric chemistry with assimilated meteorology: Model description and evaluation, J. Geophys. Res., 106, 23073-23095, 2001.

Bhave, P. V., Pouliot, G. A., and Zheng, M.: Diagnostic model evaluation for carbonaceous $\mathrm{PM}_{2.5}$ using organic markers measured in the southeastern U.S., Environ. Sci. Technol., 41, 1577-1583, 2007.

Bond, T. C., Streets, D. G., Yarber, K. F., Nelson, S. M., Woo, J. H., and Klimont, Z.: A technology-based global inventory of black and organic carbon emissions from combustion, J. Geophys. Res., 109, D14203, doi:10.1029/2003JD003697, 2004.

Butler, T. M., Taraborrelli, D., Brhl, C., Fischer, H., Harder, H., Martinez, M., Williams, J., Lawrence, M. G., and Lelieveld, J.: Improved simulation of isoprene oxidation chemistry with the ECHAM5/MESSy chemistry-climate model: lessons from the GABRIEL airborne field campaign, Atmos. Chem. Phys., 8, 4529-4546, doi:10.5194/acp-8-4529-2008, 2008.

Cappa, C. D. and Jimenez, J. L.: Quantitative estimates of the volatility of ambient organic aerosol, Atmos. Chem. Phys. Discuss., 10, 1901-1938, doi:10.5194/acpd-10-1901-2010, 2010.

Chan, A. W. H., Kautzman, K. E., Chhabra, P. S., Surratt, J. D., Chan, M. N., Crounse, J. D., Krten, A., Wennberg, P. O., Flagan, R. C., and Seinfeld, J. H.: Secondary organic aerosol formation from photooxidation of naphthalene and alkylnaphthalenes: implications for oxidation of intermediate volatility organic compounds (IVOCs), Atmos. Chem. Phys., 9, 3049-3060, doi:10.5194/acp-9-3049-2009, 2009.
Chhabra, P. S., Flagan, R. C., and Seinfeld, J. H.: Elemental analysis of chamber organic aerosol using an aerodyne high-resolution aerosol mass spectrometer, Atmos. Chem. Phys., 10, 4111-4131, doi:10.5194/acp-10-4111-2010, 2010.

Chung, S. H. and Seinfeld, J. H.: Global distribution and climate forcing of carbonaceous aerosols, J. Geophys. Res., 107, 4407, doi:10.1029/2001JD001397, 2002.

Cooke, W. F., Liousse, C., Cachier, H., and Feichter, J.: Construction of a $1^{\circ} \times 1^{\circ}$ fossil fuel emission data set for carbonaceous aerosol and implementation and radiative impact in the ECHAM4 model, J. Geophys. Res., 104, 22137-22162, 1999.

de Gouw, J. A., Middlebrook, A. M., Warneke, C., Goldan, P. D., Kuster, W. C., Roberts, J. M., Fehsenfeld, F. C., Worsnop, D. R., Canagaratna, M. R., Pszenny, A. A. P., Keene, W. C., Marchewka, M., Bertman, S. B., and Bates, T. S.: Budget of organic carbon in a polluted atmosphere: Results from the New England Air Quality Study in 2002, J. Geophys. Res., 110, D16305, doi:10.1029/2004JD005623, 2005.

Donahue, N. M., Robinson, A. L., Stanier, C. O., and Pandis, S. N.: Coupled partitioning, dilution, and chemical aging of semivolatile organics, Environ. Sci. Technol., 40, 2635-2643, doi:10.1021/ES052297c, 2006.

Dzepina, K., Volkamer, R. M., Madronich, S., Tulet, P., Ulbrich, I. M., Zhang, Q., Cappa, C. D., Ziemann, P. J., and Jimenez, J. L.: Evaluation of recently-proposed secondary organic aerosol models for a case study in Mexico City, Atmos. Chem. Phys., 9, 5681-5709, doi:10.5194/acp-9-5681-2009, 2009.

Epstein, S. A., Riipinen, I., and Donahue, N. M.: A semiempirical correlation between enthalpy of vaporization and saturation concentration for organic aerosol, Environ. Sci. Technol., 44, 743748, doi:10.1021/ES902497z, 2010.

Farina, S. C., Adams, P. J., and Pandis, S. N.: Modeling global secondary organic aerosol formation and processing with the volatility basis set: implications for anthropogenic SOA, J. Geophys. Res., doi:10.1029/2009JD013046, 115, D09202, doi:10.1029/2009JD013046, 2010.

Fu, T. M., Jacob, D. J., Wittrock, F., Burrows, J. P., Vrekoussis, M., and Henze, D. K.: Global budgets of atmospheric glyoxal and methylglyoxal, and implications for formation of secondary organic aerosols, J. Geophys. Res., 113, D15303, doi:10.1029/2007JD009505, 2008.

Goldstein, A. H. and Galbally, I. E.: Known and unexplored organic constituents in the earth's atmosphere, Environ. Sci. Technol., 41, 1514-1521, doi:10.1021/ES072476p, 2007.

Grieshop, A. P., Logue, J. M., Donahue, N. M., and Robinson, A. L.: Laboratory investigation of photochemical oxidation of organic aerosol from wood fires 1: measurement and simulation of organic aerosol evolution, Atmos. Chem. Phys., 9, 1263-1277, doi:10.5194/acp-9-1263-2009, 2009.

Grieshop, A. P., Miracolo, M. A., Donahue, N. M., and Robinson, A. L.: Constraining the volatility distribution and gas-particle partitioning of combustion aerosols using isothermal dilution and thermodenuder measurements, Environ. Sci. Technol., 43, 47504756, doi:10.1021/ES8032378, 2009b.

Guenther, A., Hewitt, C. N., Erickson, D., Fall, R., Geron, C., Graedel, T., Harley, P., Klinger, L., Lerdau, M., Mckay, W. A., Pierce, T., Scholes, B., Steinbrecher, R., Tallamraju, R., Taylor, J., and Zimmerman, P.: A global-model of natural volatile organic-compound emissions, J. Geophys. Res., 100, 8873- 
8892, 1995.

Guenther, A., Karl, T., Harley, P., Wiedinmyer, C., Palmer, P. I., and Geron, C.: Estimates of global terrestrial isoprene emissions using MEGAN (Model of Emissions of Gases and Aerosols from Nature), Atmos. Chem. Phys., 6, 3181-3210, doi:10.5194/acp-63181-2006, 2006.

Hays, M. D., Geron, C. D., Linna, K. J., Smith, N. D., and Schauer, J. J.: Speciation of gas-phase and fine particle emissions from burning of foliar fuels, Environ. Sci. Technol., 36, 2281-2295, doi:10.1021/ES0111683, 2002.

Heald, C. L., Jacob, D. J., Park, R. J., Russell, L. M., Huebert, B. J., Seinfeld, J. H., Liao, H., and Weber, R. J.: A large organic aerosol source in the free troposphere missing from current models, Geophys. Res. Lett., 32, L18809, doi:10.1029/2005GL023831, 2005.

Henze, D. K. and Seinfeld, J. H.: Global secondary organic aerosol from isoprene oxidation, Geophys. Res. Lett., 33, doi:10.1029/2006GL025976, 2006.

Henze, D. K., Seinfeld, J. H., Ng, N. L., Kroll, J. H., Fu, T.-M., Jacob, D. J., and Heald, C. L.: Global modeling of secondary organic aerosol formation from aromatic hydrocarbons: highvs. low-yield pathways, Atmos. Chem. Phys., 8, 2405-2420, doi:10.5194/acp-8-2405-2008, 2008.

Hodzic, A., Jimenez, J. L., Madronich, S., Canagaratna, M. R., DeCarlo, P. F., Kleinman, L., and Fast, J.: Potential contribution of semi-volatile and intermediate volatility primary organic compounds to secondary organic aerosol in the Mexico City region, Atmos. Chem. Phys. Discuss., 10, 657-710, doi:10.5194/acpd10-657-2010, 2010.

Huffman, J. A., Docherty, K. S., Aiken, A. C., Cubison, M. J., Ulbrich, I. M., DeCarlo, P. F., Sueper, D., Jayne, J. T., Worsnop, D. R., Ziemann, P. J., and Jimenez, J. L.: Chemically-resolved aerosol volatility measurements from two megacity field studies, Atmos. Chem. Phys., 9, 7161-7182, doi:10.5194/acp-9-71612009, 2009a.

Huffman, J. A., Docherty, K. S., Mohr, C., Cubison, M. J., U1brich, I. M., Ziemann, P. J., Onasch, T. B., and Jimenez, J. L.: Chemically-resolved volatility measurements of organic aerosol from different sources, Environ. Sci. Technol., 43, 5351-5357, doi:10.1021/ES803539d, 2009b.

Jimenez, J. L., Canagaratna, M. R., Donahue, N. M., Prevot, A. S. H., Zhang, Q., Kroll, J. H., DeCarlo, P. F., Allan, J. D., Coe, H., Ng, N. L., Aiken, A. C., Docherty, K. S., Ulbrich, I. M., Grieshop, A. P., Robinson, A. L., Duplissy, J., Smith, J. D., Wilson, K. R., Lanz, V. A., Hueglin, C., Sun, Y. L., Tian, J., Laaksonen, A., Raatikainen, T., Rautiainen, J., Vaattovaara, P., Ehn, M., Kulmala, M., Tomlinson, J. M., Collins, D. R., Cubison, M. J., Dunlea, E. J., Huffman, J. A., Onasch, T. B., Alfarra, M. R., Williams, P. I., Bower, K., Kondo, Y., Schneider, J., Drewnick, F., Borrmann, S., Weimer, S., Demerjian, K., Salcedo, D., Cottrell, L., Griffin, R., Takami, A., Miyoshi, T., Hatakeyama, S., Shimono, A., Sun, J. Y., Zhang, Y. M., Dzepina, K., Kimmel, J. R., Sueper, D., Jayne, J. T., Herndon, S. C., Trimborn, A. M., Williams, L. R., Wood, E. C., Middlebrook, A. M., Kolb, C. E., Baltensperger, U., and Worsnop, D. R.: Evolution of organic aerosols in the atmosphere, Science, 326, 1525-1529, doi:10.1126/SCIENCE.1180353, 2009.
Jordan, C. E., Ziemann, P. J., Griffin, R. J., Lim, Y. B., Atkinson, R., and Arey, J.: Modeling SOA formation from OH reactions with C-8-C-17 n-alkanes, Atmos. Environ., 42, 8015-8026, doi:10.1016/J.ATMOSENV.2008.06.017, 2008.

Kaplan, I. R. and Gordon, R. J.: Non-fossil-fuel fine-particle organic-carbon aerosols in Southern California determined during the Los-Angeles aerosol characterization and source apportionment study, Aerosol. Sci. Tech., 21, 343-359, 1994.

Kautzman, K. E., Surratt, J., Chan, M. N., Chan, A. W. H., Hersey, S. P., Chhabra, P. S., Dalleska, N. F., Wennberg, P. O., Flagan, R. C., and Seinfeld, J. H.: Chemical composition of gas- and aerosol-phase products from the photooxidation of naphthalene, J. Phys. Chem. A, 114, 913-934, 2010.

Kroll, J. H., Smith, J. D., Che, D. L., Kessler, S. H., Worsnop, D. R., and Wilson, K. R.: Measurement of fragmentation and functionalization pathways in the heterogeneous oxidation of oxidized organic aerosol, Phys. Chem. Chem. Phys., 11, 8005-8014, doi:10.1039/B905289e, 2009.

Lane, T. E., Donahue, N. M., and Pandis, S. N.: Simulating secondary organic aerosol formation using the volatility basis-set approach in a chemical transport model, Atmos. Environ., 42, 7439-7451, doi:10.1016/J.ATMOSENV.2008.06.026, 2008.

Lelieveld, J., Butler, T. M., Crowley, J. N., Dillon, T. J., Fischer, H., Ganzeveld, L., Harder, H., Lawrence, M. G., Martinez, M., Taraborrelli, D., and Williams, J.: Atmospheric oxidation capacity sustained by a tropical forest, Nature, 452, 737-740, doi:10.1038/NATURE06870, 2008.

Liao, H., Henze, D. K., Seinfeld, J. H., Wu, S. L., and Mickley, L. J.: Biogenic secondary organic aerosol over the United States: Comparison of climatological simulations with observations, J. Geophys. Res., 112, D06201, doi:10.1029/2006JD007813, 2007.

Lipsky, E. M. and Robinson, A. L.: Effects of dilution on fine particle mass and partitioning of semivolatile organics in diesel exhaust and wood smoke, Environ. Sci. Technol., 40, 155-162, doi:10.1021/ES050319p, 2006.

Marley, N. A., Gaffney, J. S., Tackett, M., Sturchio, N. C., Heraty, L., Martinez, N., Hardy, K. D., Marchany-Rivera, A., Guilderson, T., MacMillan, A., and Steelman, K.: The impact of biogenic carbon sources on aerosol absorption in Mexico City, Atmos. Chem. Phys., 9, 1537-1549, doi:10.5194/acp-9-1537-2009, 2009.

Murphy, B. N. and Pandis, S. N.: Simulating the formation of semivolatile primary and secondary organic aerosol in a regional chemical transport model, Environ. Sci. Technol., 43, 47224728, doi:10.1021/ES803168a, 2009.

Ng, N. L., Kroll, J. H., Chan, A. W. H., Chhabra, P. S., Flagan, R. C., and Seinfeld, J. H.: Secondary organic aerosol formation from m-xylene, toluene, and benzene, Atmos. Chem. Phys., 7, 3909-3922, doi:10.5194/acp-7-3909-2007, 2007.

Ng, N. L., Canagaratna, M. R., Zhang, Q., Jimenez, J. L., Tian, J., Ulbrich, I. M., Kroll, J. H., Docherty, K. S., Chhabra, P. S., Bahreini, R., Murphy, S. M., Seinfeld, J. H., Hildebrandt, L., DeCarlo, P. F., Lanz, V. A., Prevot, A. S. H., Dinar, E., Rudich, Y., and Worsnop, D. R.: Organic aerosol components observed in worldwide datasets from aerosol mass spectrometry, Atmos. Chem. Phys. Discuss., 9, 27745-27789, doi:10.5194/acpd-927745-2009, 2009. 
Odum, J. R., Hoffmann, T., Bowman, F., Collins, D., Flagan, R. C., and Seinfeld, J. H.: Gas/particle partitioning and secondary organic aerosol yields, Environ. Sci. Technol., 30, 2580-2585, 1996.

Offenberg, J. H., Kleindienst, T. E., Jaoui, M., Lewandowski, M., and Edney, E. O.: Thermal properties of secondary organic aerosols, Geophys. Res. Lett., 33, L03816, doi:10.1029/2005GL024623, 2006.

Pankow, J. F.: An absorption-model of gas-particle partitioning of organic-compounds in the atmosphere, Atmos. Environ., 28, 185-188, 1994.

Park, R. J., Jacob, D. J., Chin, M., and Martin, R. V.: Sources of carbonaceous aerosols over the United States and implications for natural visibility, J. Geophys. Res., 108(D12), 4355, doi:10.1029/2002JD003190, 2003.

Park, R. J., Jacob, D. J., Field, B. D., Yantosca, R. M., and Chin, M.: Natural and transboundary pollution influences on sulfate-nitrate-ammonium aerosols in the United States: Implications for policy, J. Geophys. Res., 109, D15204, doi:10.1029/2003JD004473, 2004.

Park, R. J., Jacob, D. J., Kumar, N., and Yantosca, R. M.: Regional visibility statistics in the United States: Natural and transboundary pollution influences, and implications for the Regional Haze Rule, Atmos. Environ., 40, 5405-5423, doi:10.1016/J.ATMOSENV.2006.04.059, 2006.

Presto, A. A., Miracolo, M. A., Kroll, J. H., Worsnop, D. R., Robinson, A. L., and Donahue, N. M.: Intermediate-volatility organic compounds: A potential source of ambient oxidized organic aerosol, Environ. Sci. Technol., 43, 4744-4749, doi:10.1021/ES803219q, 2009.

Pye, H. O. T., Liao, H., Wu, S., Mickley, L. J., Jacob, D. J., Henze, D. K., and Seinfeld, J. H.: Effect of changes in climate and emissions on future sulfate-nitrate-ammonium aerosol levels in the United States, J. Geophys. Res., 114, D01205, doi:10.1029/2008JD010701, 2009.

Rind, D., Lerner, J., Jonas, J., and McLinden, C.: Effects of resolution and model physics on tracer transports in the NASA Goddard Institute for Space Studies general circulation models, J. Geophys. Res., 112, D09315, doi:10.1029/2006JD007476, 2007.

Robinson, A. L., Donahue, N. M., Shrivastava, M. K., Weitkamp, E. A., Sage, A. M., Grieshop, A. P., Lane, T. E., Pierce, J. R., and Pandis, S. N.: Rethinking organic aerosols: Semivolatile emissions and photochemical aging, Science, 315, 1259-1262, doi:10.1126/SCIENCE.1133061, 2007.

Sander, R.: Compilation of Henry's Law constants for inorganic and organic species of potential importance in environmental chemistry (version 3), http://www.henrys-law.org, 1999.

Schauer, J. J., Kleeman, M. J., Cass, G. R., and Simoneit, B. R. T.: Measurement of emissions from air pollution sources. 3. C-1C-29 organic compounds from fireplace combustion of wood, Environ. Sci. Technol., 35, 1716-1728, doi:10.1021/ES001331e, 2001.

Schauer, J. J., Kleeman, M. J., Cass, G. R., and Simoneit, B. R. T.: Measurement of emissions from air pollution sources. 5. C-1-C32 organic compounds from gasoline-powered motor vehicles, Environ. Sci. Technol., 36, 1169-1180, doi:10.1021/ES0108077, 2002.

Schichtel, B. A., Malm, W. C., Bench, G., Fallon, S., McDade, C. E., Chow, J. C., and Watson, J. G.: Fossil and contem- porary fine particulate carbon fractions at 12 rural and urban sites in the United States, J. Geophys. Res., 113, D02311, doi:10.1029/2007JD008605, 2008.

Sheesley, R. J., Kruså, M., Krecl, P., Johansson, C., and Gustafsson, Ö.: Source apportionment of elevated wintertime PAHs by compound-specific radiocarbon analysis, Atmos. Chem. Phys., 9, 3347-3356, doi:10.5194/acp-9-3347-2009, , 2009.

Shrivastava, M. K., Lipsky, E. M., Stanier, C. O., and Robinson, A. L.: Modeling semivolatile organic aerosol mass emissions from combustion systems, Environ. Sci. Technol., 40, 26712677, doi:10.1021/ES0522231, 2006.

Shrivastava, M. K., Lane, T. E., Donahue, N. M., Pandis, S. N., and Robinson, A. L.: Effects of gas particle partitioning and aging of primary emissions on urban and regional organic aerosol concentrations, J. Geophys. Res., 113, D18301, doi:10.1029/2007JD009735, 2008.

Szidat, S.: Radiocarbon analysis of carbonaceous aerosols: Recent developments, Chimia, 63, 157-161, doi:10.2533/CHIMIA.2009.157, 2009.

Turpin, B. J. and Lim, H. J.: Species contributions to $\mathrm{PM}_{2.5}$ mass concentrations: Revisiting common assumptions for estimating organic mass, Aerosol. Sci. Tech., 35, 602-610, 2001.

van der Werf, G. R., Randerson, J. T., Giglio, L., Collatz, G. J., Kasibhatla, P. S., and Arellano Jr., A. F.: Interannual variability in global biomass burning emissions from 1997 to 2004, Atmos. Chem. Phys., 6, 3423-3441, doi:10.5194/acp-6-3423-2006, 2006.

Weber, R. J., Sullivan, A. P., Peltier, R. E., Russell, A., Yan, B., Zheng, M., de Gouw, J., Warneke, C., Brock, C., Holloway, J. S., Atlas, E. L., and Edgerton, E.: A study of secondary organic aerosol formation in the anthropogenicinfluenced southeastern United States, J. Geophys. Res., 112, D13302, doi:10.1029/2007JD008408, 2007.

Wesely, M. L.: Parameterization of surface resistances to gaseous dry deposition in regional-scale numerical-models, Atmos. Environ., 23, 1293-1304, 1989.

Wu, S. L., Mickley, L. J., Jacob, D. J., Logan, J. A., Yantosca, R. M., and Rind, D.: Why are there large differences between models in global budgets of tropospheric ozone?, J. Geophys. Res., 112, D05302, doi:10.1029/2006JD007801, 2007.

Wu, S. L., Mickley, L. J., Leibensperger, E. M., Jacob, D. J., Rind, D., and Streets, D. G.: Effects of 2000-2050 global change on ozone air quality in the United States, J. Geophys. Res., 113, D06302, doi:10.1029/2007JD008917, 2008.

Zhang, L. M., Gong, S. L., Padro, J., and Barrie, L.: A sizesegregated particle dry deposition scheme for an atmospheric aerosol module, Atmos. Environ., 35, 549-560, 2001.

Zhang, Q., Worsnop, D. R., Canagaratna, M. R., and Jimenez, J. L.: Hydrocarbon-like and oxygenated organic aerosols in Pittsburgh: insights into sources and processes of organic aerosols, Atmos. Chem. Phys., 5, 3289-3311, doi:10.5194/acp-5-32892005, 2005.

Zhang, Q., Jimenez, J. L., Canagaratna, M. R., Allan, J. D., Coe, H., Ulbrich, I., Alfarra, M. R., Takami, A., Middlebrook, A. M., Sun, Y. L., Dzepina, K., Dunlea, E., Docherty, K., DeCarlo, P. F., Salcedo, D., Onasch, T., Jayne, J. T., Miyoshi, T., Shimono, A., Hatakeyama, S., Takegawa, N., Kondo, Y., Schneider, J., Drewnick, F., Borrmann, S., Weimer, S., Demerjian, K., Williams, P., Bower, K., Bahreini, R., Cottrell, L., 
Griffin, R. J., Rautiainen, J., Sun, J. Y., Zhang, Y. M., and Worsnop, D. R.: Ubiquity and dominance of oxygenated species in organic aerosols in anthropogenically-influenced Northern Hemisphere midlatitudes, Geophys. Res. Lett., 34, L13801, doi:10.1029/2007GL029979, 2007.
Zhang, Y. X. and Tao, S.: Global atmospheric emission inventory of polycyclic aromatic hydrocarbons (PAHs) for 2004, Atmos. Environ., 43, 812-819, doi:10.1016/J.ATMOSENV.2008.10.050, 2009. 